Document downloaded from:

http://hdl.handle.net/10251/153367

This paper must be cited as:

Bartual-Murgui, C.; Piñeiro-López, L.; Valverde-Muñoz, FJ.; Muñoz Roca, MDC.; Seredyuk, M.; Real, JA. (2017). Chiral and Racemic Spin Crossover Polymorphs in a Family of Mononuclear Iron(II) Compounds. Inorganic Chemistry. 56(21):13535-13546. https://doi.org/10.1021/acs.inorgchem.7b02272

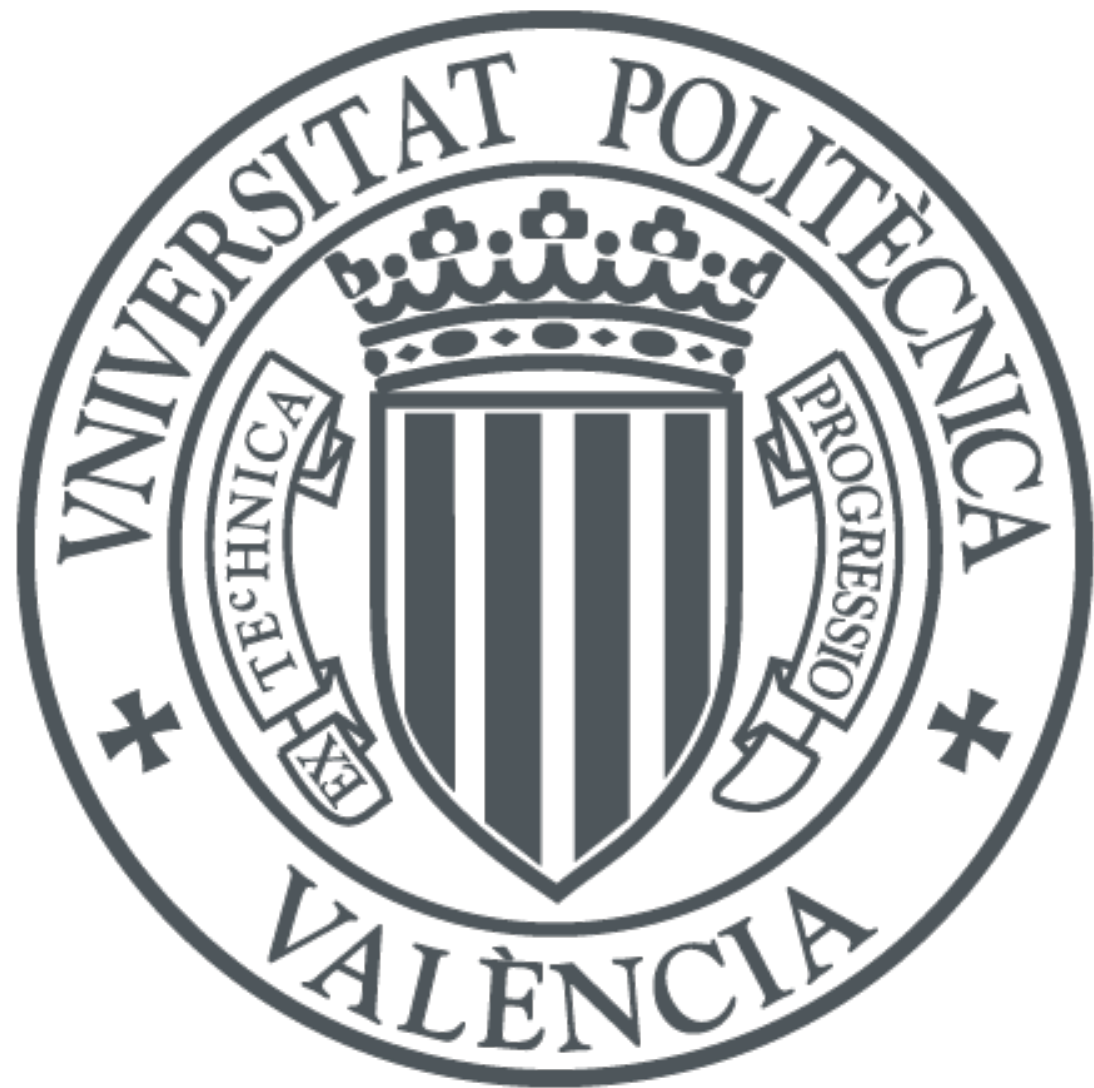

The final publication is available at

https://doi.org/10.1021/acs.inorgchem.7b02272

Copyright American Chemical Society

Additional Information

This document is the Accepted Manuscript version of a Published Work that appeared in final form in Inorganic Chemistry, copyright (C) American Chemical Society after peer review and technical editing by the publisher.

To access the final edited and published work see https://doi.org/10.1021/acs.inorgchem.7b02272 


\title{
Chiral and Racemic Spin Crossover Polymorphs in a Family of Mononuclear Iron(II) Compounds
}

\author{
Carlos Bartual-Murgui, ${ }^{* \dagger}$ Lucía Piñeiro-Lopez, $^{\dagger}$ F. Javier Valverde-Muñoz, ${ }^{\dagger}$ M. Carmen Muñoz, ${ }^{\ddagger}$ \\ Maksym Seredyuk, ${ }^{\dagger, \S}$ and José Antonio Real ${ }^{\star, \dagger}(0)$ \\ †Institut de Ciencia Molecular (ICMol), Departament de Química Inorganica, Universitat de Valencia, C/Catedratico José Beltrán \\ Martínez, 2, 46980 Paterna (Valencia), Spain \\ ${ }^{\ddagger}$ Departamento de Física Aplicada, Universitat Politecnica de Valencia, Camino de Vera s/n, 46022 Valencia, Spain

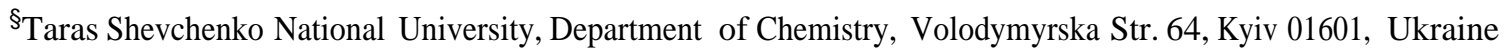 \\ * Supporting Information
}

ABSTRACT: Understanding the origin of cooperativity and the equilibrium temperature of transition $\left(\mathrm{T}_{1 / 2}\right)$ displayed by the spin-crossover ( $\mathrm{SCO}$ ) compounds as well as controlling these parameters are of paramount importance for future applications. For this task, the occurrence of polymorphism, presented by a number of SCO complexes, may provide deep insight into the influence of the supramolecular organization on the SCO behavior. In this context, herein we present a novel family of mononuclear octahedral $\mathrm{Fe}^{\mathrm{II}}$ complexes with formula cis$\left[\mathrm{Fe}(\right.$ bqen $\left.)(\mathrm{NCX})_{2}\right]$, where bqen is the chelating tetradentate ligand N,N'-bis(8-quinolyl)ethane-1,2-diamine and $\mathrm{X}=\mathrm{S}$, Se. Depending on the preparation method, these compounds crystallize in either the orthorhombic or the trigonal symmetry
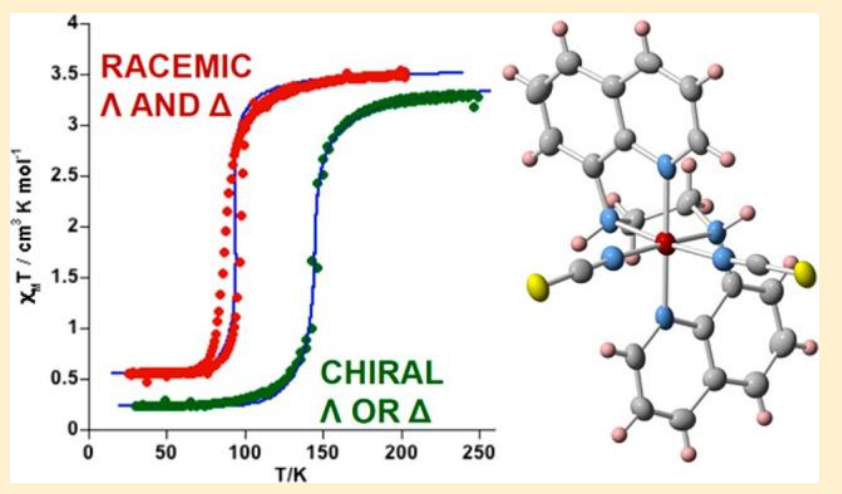
systems. While the orthorhombic phase is composed of a racemic mixture of mononuclear complexes (polymorph I), the trigonal phase contains only one of the two possible enantiomers $(\Lambda$ or $\Delta)$, thereby generating a chiral crystal (polymorph II). The four derivatives undergo SCO behavior with well-differentiated $\mathrm{T}_{1 / 2}$ values occurring in the interval $90-233 \mathrm{~K}$. On one hand, $\mathrm{T}_{1 / 2}$ is about $110 \mathrm{~K}$ (polymorph I) and $87 \mathrm{~K}$ (polymorph II) higher for the selenocyanate derivatives in comparison to those for their thiocyanate counterparts. These differences in $\mathrm{T}_{1 / 2}$ are ascribed not only to the higher ligand field induced by the selenocyanate anion but also to a remarkable difference in the structural reorganization of the $\left[\mathrm{FeN}_{6}\right]$ coordination core upon SCO. Likewise, the higher cooperativity observed for the thiocyanate derivatives seems to be related to their stronger intermolecular interactions within the crystal. On the other hand, $\mathrm{T}_{1 / 2}$ is about 53 $\mathrm{K}$ (thiocyanate) and $29 \mathrm{~K}$ (selenocyanate) higher for the trigonal polymorph II in comparison to those for the orthorhombic polymorph I. These differences, and the smalp changes observed in cooperativity, stem from the slightly different hetero- and homochiral crystal packing generated by the cis-[Fe(bqen)(NCX $\left.)_{2}\right]$ molecules, which determines subtle adaptations in the intermolecular contacts and the $\mathrm{Fe}^{\mathrm{II}}$ coordination core.

\section{INTRODUCTION}

The spin-crossover (SCO) phenomenon is an outstanding example of molecular switching displayed by some coordination complexes containing transition metals with $3 d^{4}-3 d^{7}$ electronic configurations. Among them, octahedral SCO Fe $\mathrm{Fe}^{\mathrm{II}}\left(3 \mathrm{~d}^{6}\right)$ complexes have been, largely, the most targeted and investigated systems. This is likely because the transition between the low-spin ( $\mathrm{LS} ; \mathrm{S}=0, \mathrm{t}_{2 \mathrm{~g}}{ }^{6} \mathrm{e}_{\mathrm{g}}{ }^{0}$ ) and the high-spin (HS; $S=2, t_{2 g}{ }^{4} \mathrm{e}_{\mathrm{g}}{ }^{2}$ ) states is accompanied by measurable changes in the magnetic, electrical, and optical properties. ${ }^{1}$

Even if thermally driven spin transition compounds have been traditionally the most studied and published systems, the spin state change can also be triggered by the modification of pressure, ${ }^{2}$ a magnetic field, ${ }^{3}$ light irradiation, ${ }^{4}$ or guest adsorption processes. ${ }^{5}$ These switchable properties make these complexes excellent candidates for memories and sensor applications. $^{1 \mathrm{f}, 6}$

At the macroscopic scale, the transmission efficiency of the spin-state change within the material is determined by its cooperativity. Hence, materials presenting low cooperativity (weak coupling between SCO centers) will display smooth SCO curves, whereas those presenting high cooperativity (strong coupling between SCO centers) will exhibit abrupt spin transitions. ${ }^{1 b, 7}$ Thus, in principle, cooperative transitions are expected for extended polymeric systems (1D-3D frameworks) in which the SCO metal ions are connected through rigid bonds, allowing an efficient propagation of the 
spin state change. However, it is well documented that, in the case of discrete mononuclear complexes (OD systems), the lack of covalent connections between $\mathrm{Fe}^{\mathrm{II}}$ centers does not mean, necessarily, a low degree of cooperativity. This is because the packing of the molecular complexes can be established on the basis of a strong and dense lattice of intermolecular forces (i.e., $\pi \cdots \pi, \pi \cdots \mathrm{HC}$, and/or hydrogen bonds) conferring high cooperative effects. ${ }^{8}$

The transition temperature $\left(T_{1 / 2}\right)$, defined as the temperature of equilibrium at which the molar fraction of the HS centers is equal to that of the LS centers $\left(\gamma_{\mathrm{HS}}=\gamma_{\mathrm{LS}}=0.5\right)$ is, together with the cooperativity, the other main parameter defining the SCO behavior. As was mentioned before, the latter depends on how efficient the connectivity between the $\mathrm{Fe}^{\mathrm{II}}$ centers is, whereas the former is rather related to the octahedral environment of the metal center. Indeed, weak ligand fields are known to stabilize the HS configuration and consequently they lead to low transition temperatures. Conversely, strong ligand fields stabilizes the LS configuration and drive to higher $\mathrm{T}_{1 / 2}{ }^{9}$ Nevertheless, both parameters, cooperativity and $T_{1 / 2}$, have a certain degree of interdependence, since the crystal packing may induce subtle electronic (electron-donating or -withdrawing) and/or steric (molecular distortion, chemical pressure) effects transmitted through the intermolecular contacts. Thus, the control and understanding of both parameters are key issues in the SCO research area.

Polymorphism displayed by some $\mathrm{SCO} \mathrm{Fe}^{\mathrm{II}}$ complexes (especially discrete OD systems) offers the possibility of evaluating how the intermolecular interactions influence both key parameters and constitutes a singular platform to shed light on the microscopic mechanisms that control the SCO phenomenon in the solid state. ${ }^{10}$ Most reported examples in SCO materials on polymorphism are related to the ways in which the complexes (including anions and solvents) can be packed in the crystal. In this respect, neutral complexes of the type $\left[\mathrm{Fe}(\mathrm{L})_{2}(\mathrm{NCX})_{2}\right](\mathrm{L}=$ bidentate $\alpha$-diimine ligand; $\mathrm{X}=\mathrm{S}$, $\mathrm{Se}$ ) have afforded relevant examples of polymorphism. As far as we are aware, the first example of polymorphism structurally characterized corresponds to the complex cis-[Fe(bt) $\left.)_{2}(\mathrm{NCS})_{2}\right]$ (bt $=2,2$ '-bithiazoline), which crystallizes in two different polymorphs (A and B). ${ }^{11}$ They display distinct crystal packing dominated by strong intermolecular $S \cdots S$ contacts, which drastically influence the geometry of the $\mathrm{Fe}^{\mathrm{Il}}$ coordination core. Polymorph A's coordination core, exhibiting smaller angular distortion $\theta$ and $\Sigma$ parameters $^{12}\left(\Sigma_{\mathrm{HS}}=78.75^{\circ}, \theta_{\mathrm{HS}}=230.4^{\circ}\right)$, undergoes a strong cooperative SCO centered at $181.5 \mathrm{~K}$ with a hysteresis $11.5 \mathrm{~K}$ wide, while the much more distorted $\mathrm{Fe}^{\mathrm{II}}$ coordination geometry $\left(\Sigma_{\mathrm{HS}}=85.42^{\circ}, \theta_{\mathrm{HS}}=352.8^{\circ}\right)$ of polymorph $\mathrm{B}$ stabilizes the HS state at all temperatures even at pressures as high as $1 \mathrm{GPa}^{11 \mathrm{~b}}$ Similarly, the complex trans$\left[\mathrm{Fe}(\mathrm{abpt})_{2}(\mathrm{NCX})_{2}\right] \quad(\mathrm{X}=\mathrm{S}, \mathrm{Se} ;$ abpt $=4$-amino-3,5-bis(pyridin-2-yl)-1,2,4-triazole) affords two polymorphs (A and $\mathrm{B}) .{ }^{13}$ In the polymorph $\mathrm{A}(\mathrm{X}=\mathrm{S}, \mathrm{Se})$ the abpt ligands, characterized by an intramolecular hydrogen bond between the amino group and the uncoordinated pyridine ring, are almost planar, thus favoring a one-dimensional supramolecular array of $\mathrm{Fe}^{\mathrm{II}}$ complexes held together through $\pi-\pi$ interactions. In contrast, the $\mathrm{NH}_{2} \cdots \mathrm{N}$ (pyridyl) hydrogen bond vanishes in the polymorphs $\mathrm{B}$, allowing the uncoordinated pyridyl group to deviate $34^{\circ}$ from planarity, thereby generating a distinct twodimensional network of $\pi-\pi$ interactions. ${ }^{13 b}$ Polymorphs A display a gradual SCO behavior with $\mathrm{T}_{1 / 2}=180 \mathrm{~K}(\mathrm{X}=\mathrm{S})$ and $224 \mathrm{~K}(\mathrm{X}=\mathrm{Se})$, whereas polymorphs $\mathrm{B}$ are paramagnetic at all temperatures. Although the molecular distortions presented by both polymorphs are comparable, the polymorphs B display partial disruption of the $\pi$ delocalization in the abpt ligand and slightly longer $\mathrm{Fe}-\mathrm{N}$ bond lengths. These subtle differences seem to be the reason for the different magnetic behavior. Indeed, the S derivative of polymorph B displays a SCO at 0.86 GPa similar to that of the homologous derivative of polymorph A at ambient pressure. ${ }^{13 \mathrm{c}}$

Along the same line, the complex cis-[Fe( $\left.\mathrm{PMBiA})_{2}(\mathrm{NCS})_{2}\right]$ can be obtained in two different forms, so-called polymorphs I and II. ${ }^{14}$ Even if both complexes are thermally induced spin crossover active, they present quite different SCO curve features. Indeed, while polymorph I displays a very abrupt spin crossover curve with a hysteresis $5 \mathrm{~K}$ wide centered at 167 $\mathrm{K}$, the SCO behavior of polymorph II is gradual with $\mathrm{T}_{1 / 2}=205$ $\mathrm{K}$. These two different behaviors have been explained by subtle differences in some angles of the $\mathrm{Fe}^{\mathrm{II}}$ coordination core and different $\mathrm{S} \cdots \mathrm{HC}$ intermolecular contacts established between adjacent complexes. Both parameters were demonstrated to be related to the abruptness of the spin transition curve and therefore to the cooperativity of the SCO compound.

Another reported example of SCO polymorphs is the compound fac-[Fe(dppa $\left.)_{2}(\mathrm{NCS})_{2}\right]$ (dppa is the tetradentate ligand (3-aminopropyl)bis(2-pyridylmethyl)amine). This compound crystallizes, affording three different polymorphs $(A-C)$. The magnetic susceptibility measurements revealed that while polymorphs A and B exhibit SCO at $176 \mathrm{~K}$ (gradual without hysteresis) and $116 \mathrm{~K}$ (abrupt with an $8 \mathrm{~K}$ wide hysteresis), respectively, polymorph $\mathrm{C}$ is paramagnetic at all temperatures. These differences in SCO behavior seem to be related to small differences detected in the $\mathrm{Fe}^{\mathrm{II}}$ octahedral environment and to the quite distinct packing modes displayed by each compound. ${ }^{15}$

A more recent study of polymorphism and SCO relationships reported the compound trans- $\left[\mathrm{FeL}^{\mathrm{Me}}(\mathrm{NCS})_{2}\right]$, where $\mathrm{L}^{\mathrm{Me}}$ is the tetradentate ligand N,N'-bis[(1-methyl-1,2,3-triazol-4yl)methylene]propane-1,3-diamine. ${ }^{16}$ This compound crystallizes in two different monoclinic space groups, C2/c (polymorph A) and $\mathrm{P} 2{ }_{1} / \mathrm{n}$ (polymorph B). Even if the structures of both polymorphs are very similar regarding the environment of the $\mathrm{Fe}^{\mathrm{II}}$ ion, their crystal packings are quite different, establishing a larger number of hydrogen bonds ( $\mathrm{S}$...

$\mathrm{HC}$ ) for polymorph B than for polymorph A. These additional bonds are responsible for the stabilization of the LS state in polymorph B and, therefore, its almost $100 \mathrm{~K}$ higher transition temperature.

In addition to the polymorphism, another approach to evaluate the effect of structural features on the modification of the SCO essential parameters is the comparison of isostructural compounds (i.e., chemically different compounds sharing the same structure). A relevant example is represented by the family of $\mathrm{Fe}^{\mathrm{II}}$ mononuclear compounds [ $\mathrm{Fe}\left(\mathrm{R}_{2}\right.$ bapbpy)$\left.(\mathrm{NCX})_{2}\right]$ (bapbpy = N6,N6'-bis(pyridin-2-yl)-2,2'-bipyridine$6,6^{\prime}$-diamine, $\left.\mathrm{X}=\mathrm{S}, \mathrm{Se}\right) .{ }^{17}$ In general, and as demonstrated in previous works, ${ }^{18}$ the substitution of $\mathrm{S}$ by $\mathrm{Se}$ on the $\mathrm{NCX}^{-}$ ligand leads to less cooperative SCO with higher transition temperatures because of the higher electronegativity of the former. This is, in general, the case of the $\left[\mathrm{Fe}\left(\mathrm{R}_{2}\right.\right.$ bapbpy)$(\mathrm{NCX})_{2}$ ] series with the exception of the complex derived from the bapbpy's isoquinolin-3-yl version ( $\mathrm{R}=$ phenyl), where the Se derivate is more cooperative. The lack of single-crystal X-ray data hindered an explanation for this observation, but the 
authors hypothesized that structural factors could be behind this result.

Here we report on an unprecedented example of polymorphism relating the racemic and homochiral forms of two $\mathrm{Fe}^{\mathrm{II}} \mathrm{SCO}$ complexes. More precisely, we present the synthesis and characterization of a new family of SCO mononuclear $\mathrm{Fe}^{\mathrm{II}}$ complexes of general formula cis-[Fe(bqen) $\left.(\mathrm{NCX})_{2}\right]$, bqen being the tetradentate ligand N,N'-bis(8-quinolyl)ethane-1,2diamine (Scheme 1), and $\mathrm{X}=\mathrm{S}$, Se. Both thio- and

Scheme 1. Geometrical Representation of the Ligand bqen

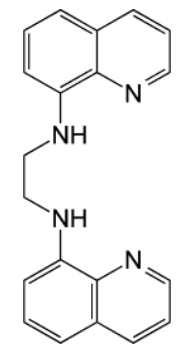

selenocyanate derivatives afford two polymorphs that crystallize in the heterochiral orthorhombic Pbca space group (polymorph I) and in the homochiral trigonal $\mathrm{P} 3_{1} 21$ (or $\mathrm{P} 3_{2} 21$ ) space group (polymorph II). Each polymorph is accessible as a pure phase by the control of the synthetic method. We also intend to correlate the different SCO temperatures and cooperativity degrees observed for each compound with the differences in the available crystal structures.

\section{RESULTS}

Synthesis. The bqen ligand was synthesized according to the method reported in the literature. ${ }^{19}$ The addition of a methanolic/ethanolic solution of bqen to a methanolic solution containing 1 equiv of $\mathrm{Fe}\left(\mathrm{SO}_{4}\right) \cdot 7 \mathrm{H}_{2} \mathrm{O}$ and 2 equiv of $\mathrm{KSCN}$ (or $\mathrm{KSeCN}$ ) led to the precipitation of a red solid labeled as 1 (2). The good reproducibility of this synthesis is worth noting, as the same products presenting the same structural and magnetic properties were obtained on repeated occasions. Powder X-ray diffraction (PXRD) patterns were also collected for 1 and 2, confirming their isostructurality (vide infra). Aiming at correlating the SCO behavior of 1 and 2 with their structure, we carried out numerous attempts to obtain single crystals of these systems. However, the majority of the liquid to liquid diffusion strategies tried for this purpose were unsuccessful, likely due to the oxidation of $\mathrm{Fe}^{\mathrm{II}}$ triggered by the basic character of ligand bqen. This resulted in the formation of brown (almost black) solutions that yielded poorly crystalline solids of the same color. In view of these difficulties, two different approaches were followed.

Substitution of $\mathrm{Fe}^{\|}$Ion with $\mathrm{Ni}^{\prime \prime}$. The goal was to obtain the crystal structure of the non-SCO-active analogous compounds cis-[Ni(bqen $\left.)(\mathrm{NCX})_{2}\right]$ and, thus, to infer useful structural information for the homologous $\mathrm{Fe}^{\mathrm{II}}$ complexes. Unexpectedly, following this strategy, square- and hexagonal-shaped single crystals were formed for both $\mathrm{S}$ and Se derivatives (Figure 1, left and middle). The four compounds show the same general formula $\left[\mathrm{Ni}(\right.$ bqen $\left.)(\mathrm{NCX})_{2}\right]$. The square-shaped thin plates with $X=S(3)$ and $X=S e$ (4) turned out to be isostructural with 1 and 2, as confirmed from comparison of the simulated single-crystal X-ray patterns for 3 and 4 with the experimental PXRD patterns for 1 and 2. The hexagonal-shaped crystals labeled $3(X=S)$ and $4(X=S e)$ exhibit different crystal structures, thereby revealing the existence of two polymorphs hereafter called polymorph I (compounds 1-4) and polymorph II (compounds 3' and 4').

Minimization of the Contact Time of Fe" with bqen before the Formation of the Complex. For this purpose, an aqueous solution of the $\mathrm{Fe}^{\mathrm{II}}$ salt was poured into the bottom of a test tube and a mixture of the KCNX salt and bqen in acetone was layered on the top. In order to slow down the mixing of the reactants, both solutions were separated by an intermediate acetone/water (1/1) layer. Under these conditions, a pure phase formed by hexagonal single crystals (see Figure 1, right) suitable for single-crystal X-ray studies was obtained in a quantitative manner for the $\mathrm{S}$ and $\mathrm{Se}$ derivatives (compounds $1^{\prime}$ and 2', respectively). The crystal analysis for 1' and 2' $\left(\mathrm{Fe}^{\mathrm{II}}\right.$ derivatives) indicated that they are isostructural with $3^{\prime}$ and $4^{\prime \prime}$ ( $\mathrm{Ni}^{\mathrm{II}}$ derivatives) and, therefore, they belong to polymorph II. Table 1 gathers a summary of all compounds obtained in this work.

Aiming at understanding the origin of the formation of these polymorphs, the precipitation reaction of each of them was performed in different mixtures of solvents. Indeed, as explained before, in the case of $\mathrm{Fe}^{\mathrm{II}}$ complexes, the use of methanol/ethanol solutions led invariably to the formation of polymorph I (1 and 2). Conversely, slow diffusion of acetone/ water solutions led to hexagonal single crystals identified as polymorph II ( $1^{\prime}$ and $\left.2^{\prime}\right)$. In view of these results, numerous attempts to crystallize polymorph $\mathrm{I}$ of the $\mathrm{Fe}^{\mathrm{II}}$ compound were carried out in ethanol/methanol medium. Unfortunately, we
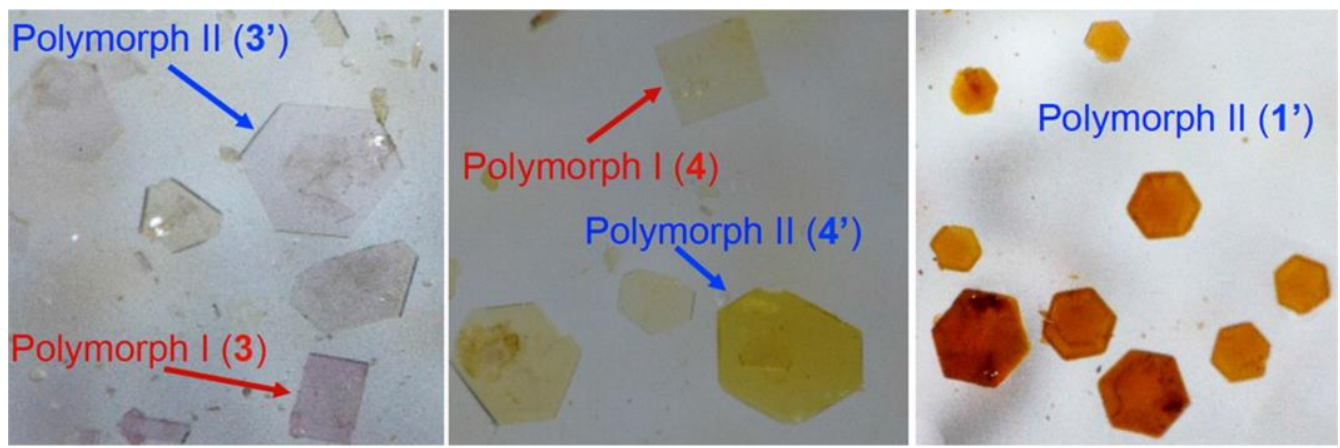

Figure 1. Optical images of the single crystals studied in this work: mixtures of polymorphs I and II for [Ni(bqen)(NCX) $\left.)_{2}\right]$ with $\mathrm{X}=\mathrm{S}\left(3\right.$ and $\left.3^{\prime}\right)$ (left), and $\mathrm{X}=\mathrm{Se}\left(4\right.$ and $\left.4^{\prime}\right)$ (middle) and a pure phase of $\left[\mathrm{Fe}(\mathrm{bqen})(\mathrm{NCS})_{2}\right]$ polymorph II (1') (right). The corresponding [Fe(bqen)(NCSe) $\left.{ }_{2}\right]$ polymorph II (2') is morphologically identical with $1^{\prime}$. 
Table 1. Summary of Compounds Presented in This Work

\begin{tabular}{cclll} 
compound & $\mathrm{M}^{\mathrm{II}}$ & $\mathrm{X}$ & texture & polymorph \\
1 & $\mathrm{Fe}$ & $\mathrm{S}$ & powder & I-orthorhombic \\
2 & $\mathrm{Fe}$ & $\mathrm{Se}$ & powder & I-orthorhombic \\
3 & $\mathrm{Ni}$ & $\mathrm{S}$ & crystals & I-orthorhombic \\
4 & $\mathrm{Ni}$ & $\mathrm{Se}$ & crystals & I-orthorhombic \\
$1^{\prime}$ & $\mathrm{Fe}$ & $\mathrm{S}$ & crystals & II-trigonal \\
$2^{\prime}$ & $\mathrm{Fe}$ & $\mathrm{Se}$ & crystals & II-trigonal \\
$3^{\prime}$ & $\mathrm{Ni}$ & $\mathrm{S}$ & crystals & II-trigonal \\
$4^{\prime}$ & $\mathrm{Ni}$ & $\mathrm{Se}$ & crystals & II-trigonal \\
\hline
\end{tabular}

did not succeed, likely due to the low solubility of the bqen ligand in these solvents. In addition, the use of other solvents such as $\mathrm{CH}_{2} \mathrm{Cl}_{2}$ and water in combination with alcohols systematically led to single crystals of polymorph II.

In the case of $\mathrm{Ni}^{\mathrm{II}}$ derivatives, no clear correlation was observed between the obtained polymorph and the solvents used (see the Experimental Section). Indeed, a mixture of both polymorphs was the most frequent result for this metal, regardless of the mixture of solvents used.

X-ray Powder Diffraction. X-ray powder diffraction (XRPD) patterns for 1 and 2 (polymorph I) and 1' and 2' (polymorph II) are depicted in Figure 2. Moreover, the

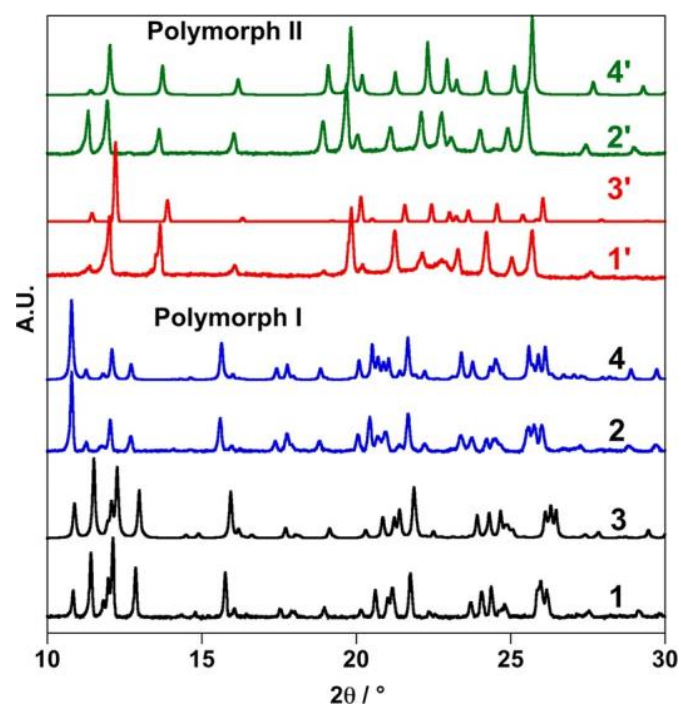

Figure 2. X-ray powder diffraction patterns. Polymorph I: 1 and 3 (X = S; black); 2 and 4 (X = Se; blue). Polymorph II: 1' and 3' $(\mathrm{X}=\mathrm{S}$; red); $2^{\prime}$ and $4^{\prime}$ ( $\mathrm{X}=\mathrm{Se}$; green). Patterns for 3, 4, 3' and $4^{\prime}$ were simulated from single-crystal data.

calculated patterns for $\mathrm{Ni}^{\mathrm{II}}$ derivative complexes 3 and 4 (polymorph I) and 3' and 4' (polymorph II), obtained from Xray single crystal diffraction data (vide infra), are also shown for comparison. The similarity between the experimental X-ray diffraction patterns for compounds $1^{\prime \prime}$ and $2^{\prime}$ (Figure 2) confirms their isostructurality (polymorph II), whereas a comparison with their corresponding simulated spectra (Figure $\mathrm{S} 1$ in the Supporting Information) indicates the presence of a pure phase. On the other hand, a comparison of the diffraction patterns of 1' and 2' with those of 1 and 2 clearly reveals that they correspond to different phases, where the latter correspond to isostructural phases (polymorph II, The 4 ' fit, as expected, the experimental powder patterns of 1 and 2 (powder compounds) and 1' and 2' (crystal compounds), confirming that they can be ascribed to polymorphs 1 and II, respectively.

Spin Crossover Behavior. Magnetic Properties. The thermal dependence of the $\mathrm{X}_{M}{ }^{\top}$ product (where $\mathrm{X}_{\mathrm{M}}$ is the molar magnetic susceptibility and $T$ is the temperature) was measured for the four $\mathrm{Fe}^{\mathrm{II}}$ compounds. The temperature scan rate was kept at $2 \mathrm{~K} \mathrm{~min}^{-1}$ for 2, 1', and 2' while it was reduced by $1 \mathrm{~K} \mathrm{~min}^{-1}$ for 1 in order to minimize possible kinetic effects. The results are depicted in Figure 3. At $250 \mathrm{~K}$, compounds 1

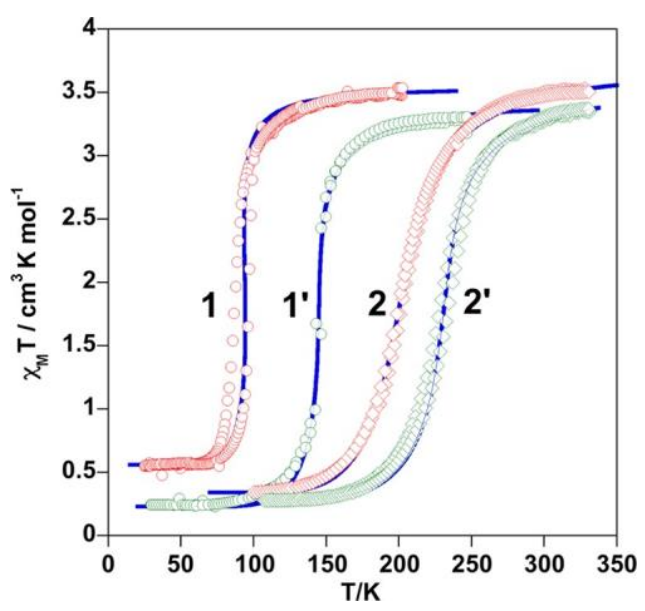

Figure 3. Magnetic behavior of compounds 1, 1', 2, and 2'.

and $1^{\prime}$ display $\mathrm{X}_{\mathrm{M}}{ }^{\top}$ values of 3.50 and $3.33 \mathrm{~cm}^{3} \mathrm{~K} \mathrm{~mol}^{-1}$, respectively, in agreement with an $\mathrm{Fe}^{\mathrm{II}}$ ion in the $\mathrm{HS}$ state. For 1 , this value remains constant down to $150 \mathrm{~K}$. At lower temperatures $\mathrm{X}_{\mathrm{M}} \uparrow$ decreases, first gradually and then abruptly, reaching a value of $0.5 \mathrm{~cm}^{3} \mathrm{~K} \mathrm{~mol}^{-1}$ at $50 \mathrm{~K}\left(\mathrm{~T}_{1 / 2} \downarrow=86 \mathrm{~K}\right)$. This result clearly indicates an almost complete HS to LS transition of the $\mathrm{Fe}^{\mathrm{II}}$ ions. The subsequent heating shows the reversibility of this process, characterized by an asymmetric hysteresis loop $\left(\mathrm{T}_{1 / 2} \uparrow=98 \mathrm{~K}\right)$. The asymmetric shape of the hysteresis and the low temperatures of the SCO suggest the occurrence of slow kinetics. In contrast, polymorph 1' presents a reversible abrupt SCO at higher temperatures $\left(\mathrm{T}_{1 / 2} \downarrow=142 \mathrm{~K}\right.$ and $T_{1 / 2} \uparrow=147$ ) with a narrower hysteresis loop $5 \mathrm{~K}$ wide.

At $350 \mathrm{~K}$, the $\mathrm{X}_{\mathrm{M}} \mathrm{T}$ values of complexes 2 and $2^{\prime}, 3.53$ and $3.36 \mathrm{~cm}^{3} \mathrm{~K} \mathrm{~mol}^{-1}$, respectively, are consistent with the almost fully populated $\mathrm{HS}$ state $\mathrm{Fe}^{\mathrm{II}}$ ion. Upon cooling, $\mathrm{X}_{\mathrm{M}} \mathrm{T}^{\mathrm{T}}$ decreases gradually for both polymorphs, reaching values of 0.34 and 0.28 $\mathrm{cm}^{3} \mathrm{~K} \mathrm{~mol}^{-1}$ at $100 \mathrm{~K}$, respectively. The almost complete SCO behaviors are characterized by $T_{1 / 2}$ values centered at ca. 204 and $235 \mathrm{~K}$ for compounds 2 and $2^{\prime}$, respectively. Despite the gradual nature of the SCO, $2^{\prime}$ displays a narrow hysteresis loop $5 \mathrm{~K}$ wide.

Calorimetric Properties. Differential scanning calorimetry (DSC) measurements were carried out for 1', 2, and 2' in the cooling and heating modes. The corresponding anomalous variation of the heat capacity $\Delta \mathrm{C}_{\mathrm{p}}$ vs $\mathrm{T}$ plots is depicted in Figure 4. Compound 1 could not be measured, since $T_{1 / 2}$ falls below the minimum temperature reached by our DSC device. The transition temperatures in the cooling $\left(T_{1 / 2} \downarrow\right)$ and heating $\left(\mathrm{T}_{1 / 2} \uparrow\right)$ modes extracted from the maximum value of the $\Delta \mathrm{C}_{\mathrm{p}}$ vs T plots are $T_{1 / 2} \downarrow=145 \mathrm{~K}$ and $\mathrm{T}_{1 / 2} \uparrow=146 \mathrm{~K}$ for $1^{\prime}, \mathrm{T}_{1 / 2} \downarrow=$ $197 \mathrm{~K}$ and $T_{1 / 2} \uparrow=200 \mathrm{~K}$ for 2 , and $T_{1 / 2} \downarrow=232 \mathrm{~K}$ and $T_{1 / 2} \uparrow=$ $233 \mathrm{~K}$ for $2^{\prime}$. These values fit satisfactorily with those obtained from the magnetic data. The average variations of enthalpy 


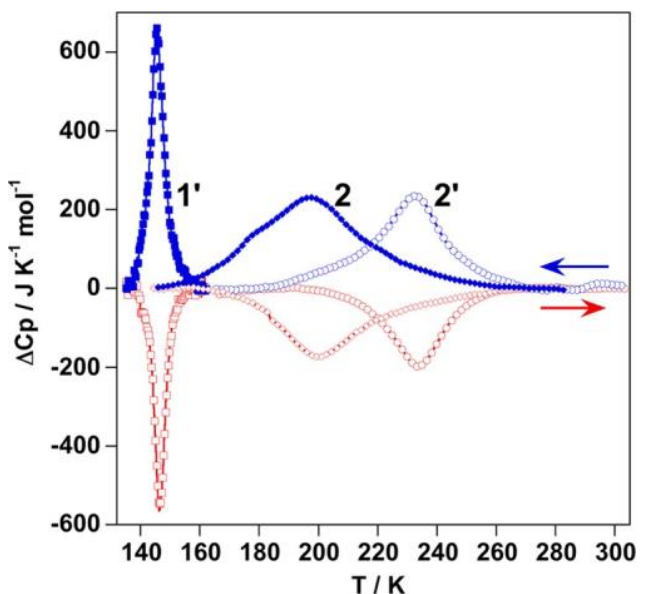

Figure 4. DSC measurements for the SCO compounds 1', 2, and 2'.

$(\Delta \mathrm{H})$ and entropy $(\Delta \mathrm{S})$ associated with the SCO calculated from the recorded DSC curves are $3.6 \mathrm{~kJ} \mathrm{~mol}^{-1}$ and $25.0 \mathrm{~J}$ $\mathrm{mol}^{-1} \mathrm{~K}^{-1}$ for $1^{\prime}, 8.5 \mathrm{~kJ} \mathrm{~mol}^{-1}$ and $43.1 \mathrm{~J} \mathrm{~mol}^{-1} \mathrm{~K}^{-1}$ for 2 , and $6.0 \mathrm{~kJ} \mathrm{~mol}^{-1}$ and $25.8 \mathrm{~J} \mathrm{~mol}^{-1} \mathrm{~K}^{-1}$ for $2^{\prime}$, respectively. As expected, $\Delta S$ is larger than that calculated from the purely electronic spin contribution $\left(\Delta S=13.38 \mathrm{~J} \mathrm{~K}^{-1} \mathrm{~mol}^{-1}\right)$ for the LS $\leftrightarrow$ HS transition. The remaining excess corresponds to the entropic contributions stemming from the molecular vibrational modes and lattice phonons. Although these $\Delta S$ values are below those expected for a complete $\mathrm{SCO}$ in an $\mathrm{Fe}^{\mathrm{II}}$ complex (50-65 $\mathrm{J} \mathrm{mol}^{-1} \mathrm{~K}^{-1}$ ), they are in line with those reported for related compounds. ${ }^{9 b, 18}$ This observation could be rationalized in terms of possible structural constraints induced by this type of rigid tetradentate ligand, which in turn could favor a certain degree of incompleteness of the SCO, particularly in the HS state. Indeed, an unexpected relatively small increase of the $\mathrm{Fe}-$ $\mathrm{N}$ average bond length upon spin transition is observed (vide infra). These results strongly contrast with those observed for the aforementioned polymorphs $\mathrm{A}$ and $\mathrm{B}$ of the complex $\left[\mathrm{Fe}\left(\mathrm{L}^{\mathrm{Me}}\right)(\mathrm{NCS})_{2}\right]$ characterized by $\Delta S$ values of about $60 \mathrm{~J} \mathrm{~K}^{-1}$ $\mathrm{mol}^{-1}$. The much larger $\Delta S$ values in the latter case may be related to the more flexible nature of the tetradentate ligand $\mathrm{L}^{\mathrm{Me}} 16$

Taking advantage of the obtained thermodynamic data, the spin conversions have been simulated and additional thermodynamic parameters have been inferred from eq 1 derived from the regular solution model: ${ }^{20}$

$$
\ln \left[\frac{1-\gamma_{\mathrm{HS}}}{\gamma_{\mathrm{HS}}-\gamma_{\mathrm{HS}}^{\mathrm{R}}}\right]=\frac{\Delta H+\Gamma\left(1+\gamma_{\mathrm{HS}}^{\mathrm{R}}-2 \gamma_{\mathrm{HS}}\right)}{R T}-\frac{\Delta S}{R}
$$

where $\Delta H, \Delta S$, and $\Gamma$ are the enthalpy and the entropy variations and the parameter accounting for the cooperative nature of the spin conversion, respectively. The molar HS fraction, $\mathrm{V}_{\mathrm{HS}}$, has been deduced from the magnetic susceptibility through eq 2:

$$
\gamma_{\mathrm{HS}}=\left[\left(\chi_{\mathrm{M}} T\right)-\left(\chi_{\mathrm{M}} T\right)_{\mathrm{LS}}\right] /\left[\left(\chi_{\mathrm{M}} T\right)_{\mathrm{HS}}-\left(\chi_{\mathrm{M}} T\right)_{\mathrm{LS}}\right]
$$

The molar fraction $Y_{\mathrm{As}}$ accounts for the HS species blocked at low temperatures and is calculated as follows (eq 3):

$$
\gamma_{\mathrm{HS}}^{\mathrm{R}}=\left(\chi_{\mathrm{M}} T\right)^{\mathrm{R}} /\left(\chi_{\mathrm{M}} T\right)^{\mathrm{HS}}
$$

$X_{M} T$ is the value of $X_{M} T$ at any temperature, $\left(X_{M} T\right)^{H S}$ is the $X_{M} T$ value of the pure HS state $(T \rightarrow \infty),\left(X_{M} T\right)^{L S} \approx 0$ is the $X_{M} T$ value of the pure $L S$, and $\left(X_{M} T\right)^{R}$ represents the residual $X_{M} T$ value due to $\mathrm{HS}$ species blocked at low temperature. Given that the $\Delta \mathrm{H}, \Delta \mathrm{S}, \mathrm{T}_{1 / 2}$, and $\left(\mathrm{X}_{\mathrm{M}} \mathrm{T}\right)^{\mathrm{R}}$ values have been estimated directly from the magnetic and/or the DSC curves, the fitted parameters were $\Gamma$ and $\left(\mathrm{X}_{\mathrm{M}} \mathrm{T}\right)^{\mathrm{HS}}$. The obtained parameters for the best simulations together with the experimental values are gathered in Table 2.

Table 2. Thermodynamic Parameters (See Text)

\begin{tabular}{lllll} 
& \multicolumn{1}{c}{1} & \multicolumn{1}{c}{$1^{\prime}$} & \multicolumn{1}{c}{2} & $2^{\prime}$ \\
$\Delta \mathrm{H} / \mathrm{J} \mathrm{mol}^{-1}$ & 4512 & 3628 & 8792 & 6063 \\
$\Delta \mathrm{S} / \mathrm{J} \mathrm{K}^{-1} \mathrm{~mol}^{-1}$ & 48 & 25 & 43.1 & 25.8 \\
$\Gamma / \mathrm{J} \mathrm{mol} \mathrm{mol}^{-1}$ & 2000 & 2645 & 2473 & 3860 \\
$\mathrm{~T}_{1 / 2}$ & 94 & 145 & 204 & 235 \\
$\mathrm{C}=\Gamma / 2 \mathrm{RT}_{1 / 2}$ & 1.27 & 1.09 & 0.73 & 0.99 \\
$\mathrm{X}_{\mathrm{M}} \mathrm{T} / \mathrm{cm}^{3} \mathrm{~K} \mathrm{~mol}^{-1}$ & 3.55 & 3.65 & 3.75 & 3.86 \\
$\mathrm{~V}_{\mathrm{HS}}^{\mathrm{R}}$ & 0.16 & 0.06 & 0.09 & 0.07 \\
\hline
\end{tabular}

Crystal Structure of Polymorph I. Given that we did not succeed in synthesizing single crystals of compounds 1 and 2, an analysis of the single-crystal structures of the homologous isostructural $\mathrm{Ni}$ derivatives (compounds 3 and 4) was undertaken. Tables S1 and S2 in the Supporting Information contain respectively a selection of relevant crystal data and $\mathrm{Ni}-$ $\mathrm{N}$ bond lengths and angles for 3 and 4.

$\mathrm{Ni}($ bqen)(NCS) 2 (3). The crystal structure of 3, determined at $120 \mathrm{~K}$, displays the orthorhombic Pbca space group. The asymmetric unit cell is formed by a $\mathrm{Ni}^{\mathrm{II}}$ center surrounded by one tetradentate bqen ligand, which adopts a cis- $\alpha$ coordination mode, and two cis $\mathrm{NCS}^{-}$groups that complete the octahedral coordination sphere (see Figure $5 \mathrm{a}$ ). The average $\mathrm{Ni}-\mathrm{N}$ bond
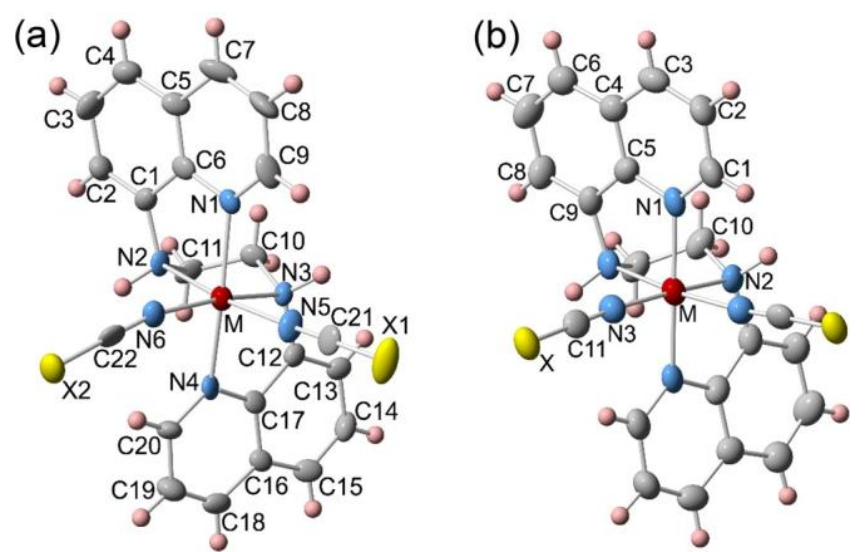

Figure 5. ORTEP representations of the coordination site for 3 and 4 $(\mathrm{M}=\mathrm{Ni}, \mathrm{X}=\mathrm{S}, \mathrm{Se}$ ) (polymorph I) (a) and for 1'-4' $(\mathrm{M}=\mathrm{Fe}, \mathrm{Ni}$; $\mathrm{X}$ $=\mathrm{S}, \mathrm{Se})(\mathrm{b})$. Thermal ellipsoids are represented at $50 \%$ probability.

length, 2.086(6) $\AA$, is characteristic of an octahedral $\mathrm{Ni}^{\mathrm{II}}$ complex. The calculated angular octahedral distortion parameters are $\Sigma=50.4(8)^{\circ}$ and $\theta=124(2)^{\circ}$. $^{12}$

The crystal packing is made up of neutral [Ni(bqen)$(\mathrm{NCSe})_{2}$ ] molecules arranged in sheets defined by parallel rows of complexes, which extend along the [100] direction and stack along the [010] direction. Within each row, the complexes display the same orientation and chirality, but the molecules of the adjacent rows are twisted approximately by an angle of $51^{\circ}$ and display the opposite enantiomeric form (Figure 6a). Within the sheets, each complex interacts with its four closest 

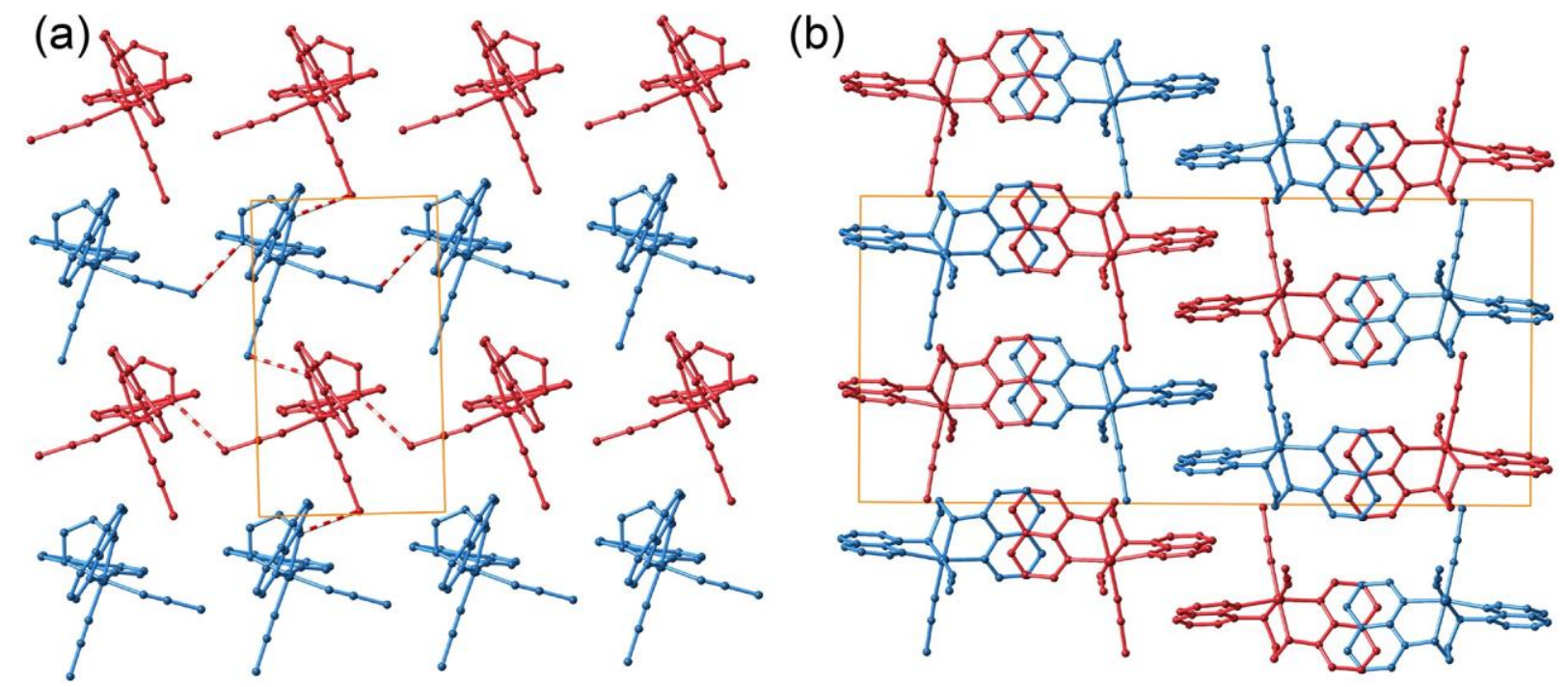

Figure 6. Compound 3 (polymorph I): (a) view of a fragment of sheet down the [001] direction; (b) view of the packing of four consecutive sheets down the [100] direction.

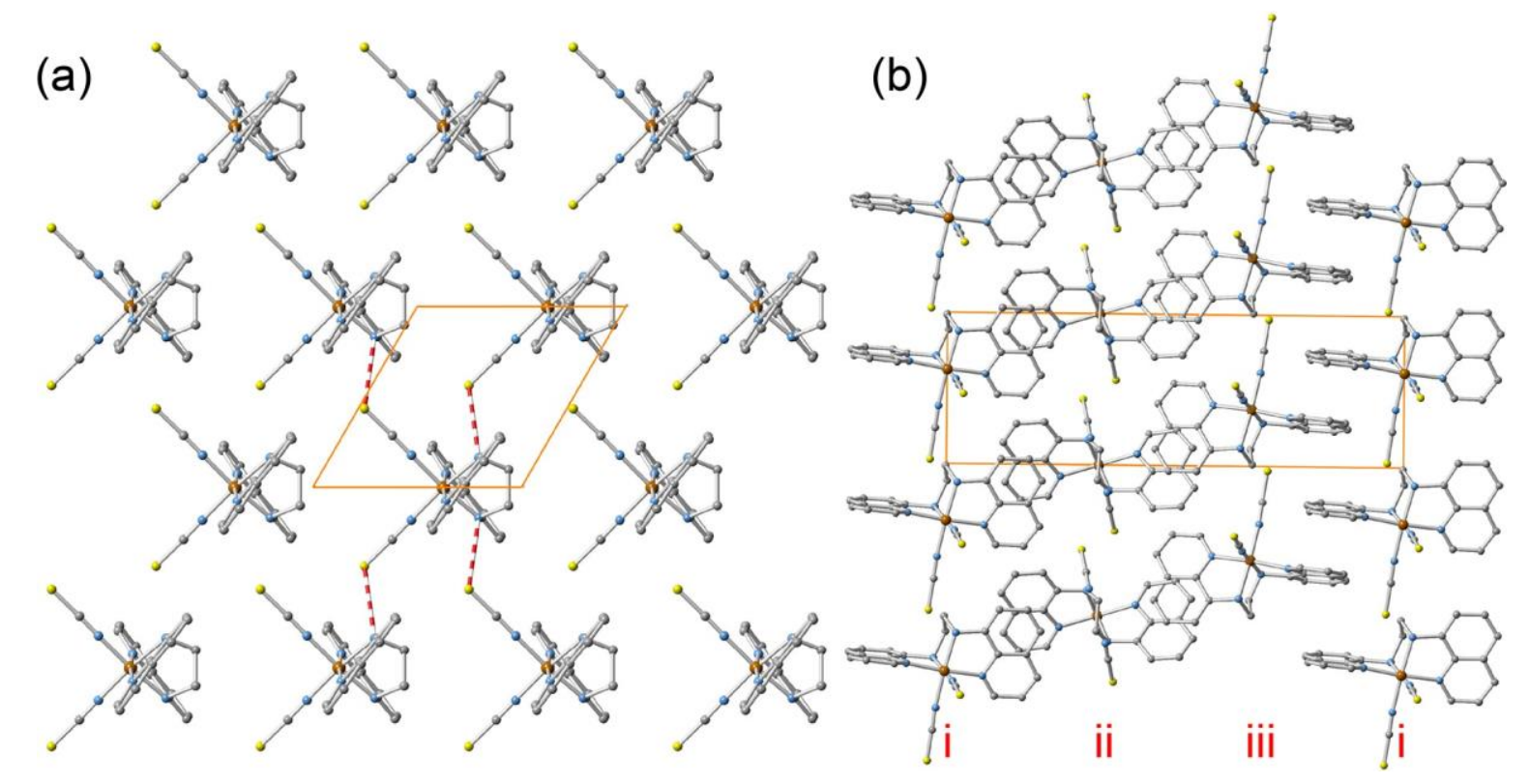

Figure 7. Compound 1' (polymorph II): perspective views down the [001] (a) and [100] (b) directions of a fragment of one sheet and a stack of four consecutive sheets. In this case the molecules all display the $\lambda$ configuration. Labels ..., $1, i i$, iii, $i$, ... indicate consecutive stacked chiral sheets related through a ternary helical axis running along [001]. Red dashed lines represent the $\mathrm{NH} \cdots \mathrm{S}$ interactions.

neighbors via $\mathrm{N}-\mathrm{H} \cdots \mathrm{S}$ hydrogen bonds, the distances being

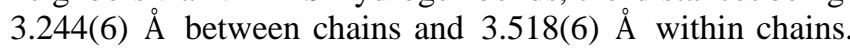
Moreover, six additional $\mathrm{C}-\mathrm{H} \cdots \mathrm{S}$ intermolecular contacts are observed between each complex and the six adjacent complexes. Two of these contacts (3.796(8) A) are established with molecules within the chain whereas the remaining four with molecules situated in adjacent chains $(3.639(7)$ and 3.712(8) §). The racemic sheets are packed along the [001] direction through the interdigitation of the quinoline moieties that stack via $\pi \cdots \pi$ interactions (Figure $6 b$ ), as is evidenced by the numerous short $\mathrm{C} \cdots \mathrm{C}$ contacts, smaller than the sum of the $\mathrm{C}$ van der Waals radii, between adjacent aromatic rings (see Table S3 and Figure S2a in the Supporting Information).

$\mathrm{Ni}(\text { bqen)(NCSe) })_{2}$ (4). The structure of 4 was also determined at $120 \mathrm{~K}$, its asymmetric unit cell being analogous to that of 3 , presenting the same orthorhombic Pbca space group and similar crystal packing. However, the following relevant changes occur on moving from the $\mathrm{S}$ derivative (3) to the Se derivative (4): (i) the average $\mathrm{Ni}-\mathrm{N}$ bond length 2.091(5) $\AA$ and the octahedral distortion parameters $\left(\Sigma=52.2(6)^{\circ}\right.$ and $\theta=$ $\left.131(2)^{\circ}\right)$ are slightly larger in relation to 3 ; (ii) the average distances of the $\mathrm{NCX} \cdots \mathrm{N}$ and $\mathrm{NCX} \cdots \mathrm{HC}$ interactions increase by 0.10 and $0.05 \AA$, respectively; (iii) the average $\pi \cdots \pi$ short contacts between adjacent sheets are slightly larger for 4 (see Table S3 and Figure S2a in the Supporting Information).

Crystal Structure of Polymorph II. Tables S1 and S4 in the Supporting Information contain respectively a selection of relevant crystal data and $\mathrm{Fe}-\mathrm{N} / \mathrm{Ni}-\mathrm{N}$ bond lengths and angles for $1^{\prime \prime}-4^{\prime}$.

$\mathrm{Fe}\left(\right.$ bqen)(NCS) ${ }_{2}\left(1^{\prime}\right)$. Hexagonal-shaped single crystals of 1' were measured at $120 \mathrm{~K}$ (dark red) and $180 \mathrm{~K}$ (orange). At 120 $\mathrm{K}$, the complex crystallizes in the trigonal chiral space group 
Table 3. Average M-N Bond Lengths $(\AA)$, Angular Distortion Parameters $\theta$ and $\Sigma(\operatorname{deg})$ of the $\left[\mathrm{Fe}^{\mathrm{II}} \mathrm{N}_{6}\right]$ Coordination Core, and Relevant Average NCX $\cdots$ HY Intermolecular Contacts $(\AA)(X=S, S e ; Y=N, C)$

\begin{tabular}{|c|c|c|c|c|c|c|}
\hline compound $(\mathrm{M} / \mathrm{X})$ & & $\mathrm{M}-\mathrm{N}$ & $\theta$ & $\Sigma$ & $\mathrm{NCX} \cdots \mathrm{HN}$ & $\mathrm{NCX} \cdots \mathrm{HC}$ \\
\hline \multicolumn{7}{|c|}{ Orthorhombic Polymorph I } \\
\hline \multicolumn{7}{|l|}{$1(\mathrm{Fe} / \mathrm{S})$} \\
\hline \multicolumn{7}{|l|}{$2(\mathrm{Fe} / \mathrm{Se})$} \\
\hline $3(\mathrm{Ni} / \mathrm{S})$ & & $2.086(6)$ & $124(2)$ & $50.4(8)$ & $3.381(6)$ & $3.716(8)$ \\
\hline $4(\mathrm{Ni} / \mathrm{Se})$ & & $2.091(5)$ & $131(2)$ & $52.2(6)$ & $3.482(5)$ & $3.765(6)$ \\
\hline \multicolumn{7}{|c|}{ Trigonal Polymorph II } \\
\hline \multirow[t]{2}{*}{$1^{\prime}(\mathrm{Fe} / \mathrm{S})$} & LS & $1.999(9)$ & 91(3) & $36(2)$ & $3.342(7)$ & $3.702(13)$ \\
\hline & HS & $2.170(6)$ & $164(2)$ & $73(1)$ & $3.366(15)$ & $3.678(17)$ \\
\hline \multirow[t]{2}{*}{$2^{\prime}(\mathrm{Fe} / \mathrm{Se})$} & LS & $1.989(12)$ & $102(6)$ & $36(2)$ & $3.405(12)$ & $3.694(20)$ \\
\hline & HS & $2.160(14)$ & $154(6)$ & $61(3)$ & $3.389(12)$ & $3.746(18)$ \\
\hline 3' (Ni/S) & & $2.094(8)$ & $121(3)$ & $50(2)$ & $3.336(11)$ & $3.707(12)$ \\
\hline $4^{\prime}(\mathrm{Ni} / \mathrm{Se})$ & & $2.086(9)$ & $128(4)$ & 49(2) & $3.423(14)$ & $3.712(17)$ \\
\hline
\end{tabular}

$\mathrm{P} 3_{1} 21$ (or $\mathrm{P} 3_{2} 21$ depending on the chirality of the complexes). The asymmetric unit includes a half-molecule of [Fe(bqen)$(\mathrm{NCS})_{2}$, generating an octahedral environment around the $\mathrm{Fe}^{\mathrm{II}}$ center through a binary axis that bisects the angle defined by the two $\mathrm{SCN}^{-}$groups, the $\mathrm{Fe}^{\mathrm{II}}$ ion, and by the two amino groups (see Figure $5 \mathrm{~b}$ ). Thus, similarly to the $\mathrm{Ni}^{\mathrm{II}}$ complexes 3 and 4 , the $\mathrm{Fe}^{\mathrm{II}}$ center is coordinated by the tetradentate ligand bqen, which adopts a cis- $\alpha$ coordination mode. The slightly distorted octahedral $\left[\mathrm{Fe}^{\mathrm{II}} \mathrm{N}_{6}\right]$ sphere $\left(\Sigma_{\mathrm{LS}}=36(2)^{\circ}\right.$ and $\theta_{\mathrm{LS}}=$ $\left.91(3)^{\circ}\right)$ is completed by two equivalent negatively charged thiocyanate ligands in a cis conformation. The average $\mathrm{Fe}-\mathrm{N}$ bond length, 1.999(9) $\AA$, is consistent with that of an $\mathrm{Fe}^{\mathrm{II}}$ ion in an LS configuration, in good agreement with the magnetic data. The packing mode of $1^{\prime}$ is made up of sheets formed by complexes [Fe(bqen)(NCS $)_{2}$ ] which display the same orientation and, therefore, the same chirality (Figure 7a). Within the sheets, each complex interacts via $\mathrm{N}(2) \mathrm{H} \cdots \mathrm{S}$ intermolecular interactions $(3.342(7) \AA$ ) with four of its six adjacent neighbors (see Figure 7a). Furthermore, eight additional S $\cdots H C$ interactions take place between each complex and its six adjacent counterparts. Four of them $(\mathrm{S} \cdots \mathrm{C}(1) \mathrm{H}=$ $3.569(12) \AA)$ occur between the four closest neighbors, whereas the remaining four interactions $(\mathrm{S} \cdots \mathrm{C}(8) \mathrm{H}=$ $3.835(13) \AA)$ are established with the two more distant neighbors.

Differently from 3 and 4 , the sheets are consecutively pillared in such a way. that they are related by. a ternary helical symmetry defining the infinite sequence ..., 1 , ii, ili, $1, \ldots$ (Figure $7 b$ ), in which all the molecules present the same chirality, thereby giving enantiopure single crystals. Nevertheless, single crystals displaying either the $P 3_{1} 21$ or $P 3_{2} 21$ space group, differing in the chirality $(\Lambda$ or $\Delta)$ of the complexes, were found within the same batch of crystals, revealing that the compound is indeed a mixture of chiral crystals. Similarly to polymorphs I, complex 1' displays short $\mathrm{C} \cdots \mathrm{C}$ contacts indicating the occurrence of intermolecular $\pi \cdots \pi$ interactions between the quinoline moieties (see Table S5 in the Supporting Information).

At $180 \mathrm{~K}$ the structure is basically the same as that at $120 \mathrm{~K}$, but the average $\mathrm{Fe}-\mathrm{N}$ bond length is $0.171 \AA$ longer. This change, although smaller than the $0.2 \AA$ expected for $\mathrm{Fe}^{\mathrm{II}} \mathrm{N}_{6}$ complexes, is consistent with the occurrence of a SCO for LS $\leftrightarrow \mathrm{HS}$, as also evidenced by the color change of the crystal from dark red to orange. In addition, and as expected, the angular octahedral distortion parameters around the $\mathrm{Fe}^{\mathrm{II}}$ center slightly increase with the LS $\leftrightarrow$ HS spin state change $\left(\Delta \Sigma_{\mathrm{HL}}=37(2)^{\circ}\right.$ and $\left.\Delta \theta_{\mathrm{HL}}=73(3)^{\circ}\right)$.
$\mathrm{Fe}\left(\right.$ bqen)(NCSe) ${ }_{2}\left(2^{\prime}\right)$. Hexagonal-shaped single crystals of 2' were measured at $120 \mathrm{~K}$ (dark red) and $280 \mathrm{~K}$ (dark orange), resulting in $2^{\prime}$ being isostructural with $1^{\prime}$. Indeed, at $120 \mathrm{~K}$ compound $2^{\prime}$ presents the same trigonal space group ( $\left.\mathrm{P}_{1}{ }_{2} 21\right)$ and an asymmetric unit similar to that of $1^{\prime}$. At this temperature, the average $\mathrm{Fe}-\mathrm{N}$ bond length of 1.989(12) $\AA$ is associated with the LS state of the $\mathrm{Fe}^{\mathrm{II}}$ ion. The angular distortion from the regular octahedral geometry of the $\left[\mathrm{Fe}^{\mathrm{II}} \mathrm{N}_{6}\right]$ core gives the parameters $\Sigma_{\mathrm{LS}}=36(2)^{\circ}$ and $\theta_{\mathrm{LS}}=102(6)^{\circ}$, which are clearly above those found for $1^{\prime}(\mathrm{LS})$. Likewise, the crystal packing observed for $2^{\prime}$ is essentially the same as that described for 1'. However, it is worth noting that, likely due to the larger volume of $\mathrm{Se}$ in comparison to that of $\mathrm{S}$, the arrangement of the mononuclear units leads, in general, to longer intermolecular contacts. For example, the $\mathrm{N}(2) \mathrm{H} \cdots \mathrm{Se}$ distances are 3.405(12) $\AA$ : namely, $0.063 \AA$ longer than for 1 '. Furthermore, the average $\mathrm{CH} \cdots \mathrm{XCN}$ intermolecular contact is practically the same as that of 1' (3.694(13) vs 3.702(20) $\AA$ ), while the $\pi \cdots \pi$ short contacts between the interdigitated quinoline moieties are slightly weaker in 2' (Table S5 in the Supporting Information).

At $280 \mathrm{~K}$ the structure of $2^{\prime}$ remains in the trigonal $\mathrm{P} 3_{1} 21$ space group. The increase in the unit cell volume $\left(\Delta V \approx 79 \AA^{3}\right)$ and the observed red to orange color change are accompanied by an increase in the average $\mathrm{Fe}-\mathrm{N}$ bond length by $0.171 \AA$ (2.160(14) $\AA$ ), which suggests the occurrence of an almost complete LS to HS transition of the Fe $\mathrm{F}^{\mathrm{II}}$ centers. Similarly to 1', the spin state change in $2^{\prime}$ also involves an increase in the angular distortion of the $\left[\mathrm{Fe}^{\mathrm{II}} \mathrm{N}_{6}\right]$ octahedral geometry $\left(\Delta \Sigma_{\mathrm{HL}}\right.$ $=25(3)^{\circ}$ and $\left.\Delta \theta_{\mathrm{HL}}=52(6)^{\circ}\right)$.

$\mathrm{Ni}($ bqen $)(\mathrm{NCX})_{2}\left(X=\mathrm{S}\left(3^{\prime}\right)\right.$, Se $\left.\left(4^{\prime}\right)\right)$. The crystal structures of $3^{\prime}$ and 4' have been measured at $120 \mathrm{~K}$ and, as in the case of compounds 1' and 2', display the trigonal space group P3 21 . Both series of compounds are isostructural, and consequently we refer to the structural description of $1^{\prime}$ and $2^{\prime}$. Concerning the $\left[\mathrm{Ni}^{\mathrm{II}} \mathrm{N}_{6}\right]$ coordination core, the average $\mathrm{Ni}-\mathrm{N}$ bond lengths are 2.094(8) $\AA(X=S)$ and 2.086(9) $\AA(X=S e)$. These values are consistent with the ionic radius of $\mathrm{Ni}^{\mathrm{II}}$ in an octahedral environment, which is approximately halfway between the ionic radii of the $\mathrm{HS}$ and $\mathrm{LS}$ states of the $\mathrm{Fe}^{\mathrm{II}}$ ion. Consistently, the $\left[\mathrm{Ni}^{\mathrm{II}} \mathrm{N}_{6}\right]$ coordination site angular distortions are approximately between values observed for the HS and LS states of the $\mathrm{Fe}^{\mathrm{II}}$ in $1^{\prime}$ and $2^{\prime}$ : namely, $\Sigma=50(2)^{\circ}$ and $\theta=121(3)^{\circ}(\mathrm{X}=\mathrm{S})$ and $\Sigma$ $=49(2)^{\circ}$ and $\theta=128(4)^{\circ}(\mathrm{X}=\mathrm{Se})$ for $3^{\prime}$ and $4^{\prime}$, respectively. The crystal packing of $3^{\prime}$ and $4^{\prime}$ shows short intermolecular 
contacts that are close to those observed for the homologous $\mathrm{Fe}^{\mathrm{II}}$ compounds.

The replacement of $S$ with $S e$ provokes important modifications in the intermolecular contacts (see Table 3 and Figure S2b in the Supporting Information). Let us highlight, for example, the increase in the NCX $\cdots \mathrm{HN}$ distances by $0.087 \AA$.

\section{DISCUSSION}

The single-crystal X-ray diffraction study carried out during this work has revealed the presence of two different types of supramolecular arrangements of the mononuclear complexes $\left[\mathrm{M}(\text { bqen })_{2}(\mathrm{NCX})_{2}\right](\mathrm{M}=\mathrm{Fe}, \mathrm{Ni}, \mathrm{X}=\mathrm{S}, \mathrm{Se})$. The two different arrangements give rise to either the orthorhombic Pbca or the trigonal $P 3_{1} 21$ (or $P 3_{2} 21$ ) space group, which have been labeled as polymorphs I and II, respectively.

By control of certain synthetic parameters, a given polymorph can be obtained instead of the other. For example, the slow diffusion of a $\mathrm{Fe}^{\mathrm{II}}$ (or $\mathrm{Ni}^{\mathrm{II}}$ ) salt solution and a solution of the bqen ligand and the corresponding $\mathrm{KXCN}$ precursor in a water/acetone medium result in the exclusive formation of polymorph II. Similarly, the precipitation reaction using these precursors leads to a microcrystalline compound also assignable to polymorph II, as long as acetone and water are used as solvents. In contrast, the same experiment performed in $\mathrm{MeOH} / \mathrm{EtOH}$ solutions involves the formation of polymorph I. This solvent-dependent effect, already observed for similar compounds, ${ }^{13}$ does not seem to be the unique aspect determining the nature of the resulting polymorph. Indeed, the slow diffusion of the $\mathrm{Ni}^{\mathrm{II}}$ salt on bqen and $\mathrm{KXCN}$ yielded mainly mixtures of both polymorphs regardless of the solvents used. All of these observations suggest that the stabilities of both polymorphs are very close, as indicated by the similar intermolecular interactions established between complexes in the crystal, and indeed, only subtle differences in the preparation mode can discriminate one polymorph from the other.

Interestingly, the subtle differences in the structural features detected for each polymorph, essentially observed in their crystal packing, seems to be governed by the presence of either a racemic mixture (polymorph I) or a pure enantiomeric form (polymorph II) of the complexes within the structure. This observation makes the title compounds particularly interesting, since the examples of synergy between chirality and SCO so far reported are relatively scarce in the literature. ${ }^{21}$ Moreover, to the best of our knowledge, this is the first SCO polymorphic system where one of the polymorphs is chiral whereas the other represents a racemic mixture.

In addition, the slightly different arrangement of the complexes observed for each polymorph has a remarkable effect on the SCO properties. To go deeper into the analysis of the magneto-structural correlations, we have analyzed, on one hand, the influence of the structural aspects on the SCO temperature $\left(\mathrm{T}_{1 / 2}\right)$ and, on the other hand, the degree of cooperativity of the SCO.

SCO Temperature. The four SCO complexes display quite distinct $\mathrm{T}_{1 / 2}$ transition temperatures: 1 (94 K), 1' (145 K), 2 (204 K), and 2' (235 K). At first glance, one can rapidly notice that the replacement of $S$ with $S e$ strongly influences $T_{1 / 2}$. Effectively, the difference in $T_{1 / 2}$ values between the selenoand thiocyanate derivatives is about $100 \mathrm{~K}$. These values are larger than those observed $(40-75 \mathrm{~K})$ for mononuclear $\left[\mathrm{Fe}(\mathrm{L})_{2}(\mathrm{NCX})_{2}\right]$ complexes, where $\mathrm{L}$ is an $\alpha$-diimine ligand such as, for example, 1,10-phenanthroline, ${ }^{22} 2,2^{\prime}$-bithiazo- line, ${ }^{11,23}$ 4-amino-3,5-bis(pyridin-2-yl)-1,2,4-triazole, ${ }^{13}$ or $\mathrm{N}$ (2'-pyridylmethylene)-4-(phenylethynyl)aniline ${ }^{24,25}$ but are on the same order of magnitude as that observed for the system derived from the ligand $\mathrm{L}=3$-(2-pyridyl)-[1,2,3]triazolo[1,5a]pyridine). ${ }^{26,27}$ This effect may be associated with two main reasons. On one hand, the higher electronegativity of the S atom, in comparison with that of Se, causes a larger electron density withdrawal from the $\mathrm{N}$ donor atom, thereby decreasing the ligand field around the $\mathrm{Fe}^{\mathrm{II}}$ center and, consequently, stabilizing the HS form. On the other hand, the octahedral distortion around the $\mathrm{Fe}^{\mathrm{II}}$ ion also influences $\mathrm{T}_{1 / 2}$. Indeed, remarkable differences can be observed in the values of the angular distortion parameters $\left(\theta\right.$ and $\Sigma$ ) when $\mathrm{SeCN}^{-}$and $\mathrm{SCN}^{-}$counterparts are compared. In general, the substitution of $\mathrm{SCN}^{-}$by $\mathrm{SeCN}^{-}$leads to larger distortion parameters (see Table 3). However, we should not take into account the absolute values of these parameters but rather the differences between the HS and LS spin states $\left(\Delta \theta_{\mathrm{HL}}\right.$ and $\left.\Delta \Sigma_{\mathrm{HL}}\right)$. Actually, it has been observed that the higher the $\Delta \theta_{\mathrm{HL}}$ and $\Delta \Sigma_{\mathrm{HL}}$ values, the lower the $\mathrm{T}_{1 / 2}{ }^{8 \mathrm{~b}}$ This is because higher $\Delta \theta_{\mathrm{HL}}$ and $\Delta \Sigma_{\mathrm{HL}}$ values imply a larger energy cost in terms of rearrangement of the ligands around the $\mathrm{Fe}^{\mathrm{II}}$ ion upon the SCO; consequently, it involves a stabilization of the HS form. Keeping this in mind, the $\left[\Delta \theta_{\mathrm{HL}} ; \Delta \Sigma_{\mathrm{HL}}\right]$ values observed for $1^{\prime}\left[73(3)^{\circ} ; 37(2)^{\circ}\right]$ are about $24 \%$ higher than for $2^{\prime}\left[52(6)^{\circ} ; 25(3)^{\circ}\right]$ and, therefore, this extra octahedral distortion in $1^{\prime}$ may contribute to the observed large $\mathrm{T}_{1 / 2}$ difference $(90 \mathrm{~K})$ between both compounds. Although the same comparison cannot be carried out between 1 and 2 , due to the lack of single crystals of these compounds, even larger differences in $\left[\Delta \theta_{\mathrm{HL}} ; \Delta \Sigma_{\mathrm{HL}}\right]$ values between $\mathrm{SCN}^{-}$and $\mathrm{SeCN}^{-}$derivatives should be expected, taking into account that the difference in $T_{1 / 2}$ is even higher $(110 \mathrm{~K})$.

In view of the lack of single-crystal X-ray information for 1 and 2 (polymorph I), a direct correlation between $\left[\Delta \theta_{\mathrm{HL}}\right.$; $\left.\Delta \Sigma_{\mathrm{HL}}\right]$ and the difference in $\mathrm{T}_{1 / 2}$ between the two different polymorphs 1 and 1' (56 K) or 2 and 2' (29 K) was not possible. However, the $[\theta ; \Sigma]$ values for the $\mathrm{Ni}^{\mathrm{II}}$ derivatives, 3 [124(2); 50.4(8)], 3' [121(3); 50(2)], 4 [131(2); 52.2(6)], and $4^{\prime}[128(4) ; 49(2)]$, are very similar, indicating that the influence of the crystal packing on the angular distortion of the $\left[\mathrm{Ni}^{\mathrm{II}} \mathrm{N}_{6}\right]$ core is negligible. If we extrapolate this situation to the $\mathrm{Fe}^{\mathrm{II}}$ title compounds, the differences in $\mathrm{T}_{1 / 2}$ between the two polymorphs should be tentatively attributed to larger values of the $\left[\Delta \theta_{\mathrm{HL}} ; \Delta \Sigma_{\mathrm{HL}}\right]$ parameters for polymorph I. It is $\mathrm{I}_{\text {INorth }}$ bond lengths for $\mathrm{M}^{\mathrm{II}}=\mathrm{Ni}\left(3,3^{\prime}, 4,4^{\prime}\right)$ and $\mathrm{Fe}\left(1^{\prime}, 2^{\prime}\right)$ are observed and, consequently, this situation can also be extrapolated to 1 and 2, suggesting that the $\mathrm{Fe}-\mathrm{N}$ bond lengths have a minor influence on $\mathrm{T}_{1 / 2}$.

Cooperativity. The measurements of the magnetic properties (Figure 3) of the cis-[Fe(bqen)( $\left.\mathrm{NCX}_{2}\right]$ complexes have revealed two well-differentiated types of $\mathrm{SCO}$ behaviors: a rather abrupt spin transition observed for compounds 1 and 1' and a less abrupt conversion between the HS and the LS states registered for compounds 2 and $2^{\prime}$. It seems, hence, that the selenocyanate ligand favors gradual spin transitions whereas the coordination of thiocyanate ligands leads to first-order transitions. Indeed, the values of cooperativity calculated from
simulations of the magnetic curves, defined as $\mathrm{C}=/ 2 \mathrm{RT} \mathrm{T}_{1 / 2}$, are $1.27(1), 1.09\left(1^{\prime}\right), 0.73(2)$, and 0.99 (2') (Table 2) and thereby are consistent with these observations. Thus, aiming at establishing a correlation between the observed cooperativity 
and the structural aspects, we have analyzed the main parameters extracted from the available X-ray data. More specifically, we have focused on the comparison between the $\mathrm{Ni}^{\mathrm{II}}$ complex structures $3\left(3^{\prime}\right)$ (S derivatives) and 4 (4') (Se derivatives), since they are isostructural with $1\left(1^{\prime}\right)$ and $2\left(2^{\prime}\right)$, respectively. The length of the intermolecular interaction NCX $\cdots \mathrm{HN}$ seems to be behind the observations explained above, as it presents values of 3.381(3) (3.336(11)) $\AA$ and 3.482(5) (3.423(14)) $\AA$ for 3 ( $\left.3^{\prime}\right)$ and 4.(4'), respectively, and therefore a difference of ca. $0.1 \mathrm{~A}$. In addition, the $\pi \cdots \pi$ stacking interactions are also stronger for the thiocyanate derivatives and may enhance the cooperativity of these complexes.

Compounds 2 and 2' exhibit a subtle difference in cooperativity ( $C=0.73$ and 0.99 , respectively), which may originate in their different packing modes. Indeed, the slight differences observed in the NCX …HN (3.482(5) $\AA$ (4) and 3.423(14) $\left.\AA\left(4^{\prime}\right)\right)$ and NCX $\cdots$ HC distances (3.765(6) $\AA$ (4) and 3.712(17) $\AA\left(4^{\prime}\right)$ ) for their $\mathrm{Ni}^{\mathrm{II}}$ counterparts support this observation. However, this correlation is not observed for 1 and 1'. Indeed, the former shows higher cooperativity $(\mathrm{C}=1.27$ vs 1.01) despite the larger $\mathrm{NCX} \cdots \mathrm{HN}$ and $\mathrm{NCX} \cdots \mathrm{HC}$ intermolecular contacts observed for the counterpart 3 . This larger $\mathrm{C}$ value for 1 is most likely overestimated due to kinetic effects associated with the low $\mathrm{T}_{1 / 2}(<100 \mathrm{~K})$ values. These kinetics are responsible for the asymmetric appearance and width of the thermal hysteresis that overestimates the cooperativity parameter.

\section{CONCLUSION}

An unprecedented family of mononuclear complexes $\left[\mathrm{M}^{\mathrm{II}}\right.$ (bqen) $\left.(\mathrm{NCX})_{2}\right]\left(\mathrm{M}^{\mathrm{II}}=\mathrm{Fe}, \mathrm{Ni} ; \mathrm{X}=\mathrm{S}, \mathrm{Se}\right)$ based on the tetradentate chelating ligand bqen has been synthesized and characterized. Single-crystal X-ray studies have revealed that, depending on the synthetic procedure, these compounds $(\mathrm{X}=$ $\mathrm{S}, \mathrm{Se}$ ) crystallize in two different crystal systems leading to two types of polymorphs (I and II). While polymorph I crystallizes in the orthorhombic space group Pbca, polymorph II displays a trigonal $\mathrm{P}_{3} 21$ (or $\mathrm{P}_{2} 21$ ) space group differing mainly in the packing mode. Interestingly, the orthorhombic phase presents a racemic $\Lambda-\Delta$ mixture of chiral cis- $\left[\mathrm{M}^{\mathrm{II}}(\right.$ bqen $\left.)(\mathrm{NCX})_{2}\right]$ complexes. In contrast, the trigonal phase is built from only one enantiomer. The four $\mathrm{Fe}^{\mathrm{II}}$ derivatives undergo $\mathrm{SCO}$ behavior, enabling, for the first time, correlation of the SCO properties with their racemic and chiral polymorphic forms. Although there are no sharp differences between the short intermolecular contacts of both polymorphs, it is important to point out that the crystal packing generated by the chiral polymorphs, for $X=S$, Se, favors higher $T_{1 / 2}$ values in comparison to the corresponding racemic forms. Our results suggest that the differences in the crystal packing of each polymorph are subtly transferred to the $\left[\mathrm{Fe}^{\mathrm{II}} \mathrm{N}_{6}\right]$ core and reflected in the change in the angular distortion parameters $\Delta \Sigma_{\text {HL }}$ and $\Delta \Theta_{\text {fL }}$ upon the $\mathrm{LS} \leftrightarrow$. HS transition, which change and hence a distinct $T_{1 / 2}$ value. This mechanism is, in part, responsible for the large change in $T_{1 / 2}$ on moving from the $\mathrm{NCS}^{-}$to the $\mathrm{NCSe}^{-}$derivatives in each polymorph, the other important influence being the electronic effects derived from the substitution of S with Se in the $\mathrm{NCX}^{-}$group. Finally, the small differences found in cooperativity for the four compounds can be explained by taking into account the effect of the $S \leftrightarrow$ Se replacement on the intermolecular interactions and the different crystal packing between the two polymorphs.

\section{EXPERIMENTAL SECTION}

Materials. The ligand N,N'-bis(8-quinolyl)ethane-1,2-diamine (bqen) was obtained using the same synthesis conditions reported elsewhere. ${ }^{19}$

cis-[Fe(bqen)(NCS) $)_{2}$ (1, Polymorph I). A solution of bqen (36.4 $\mathrm{mg})$ in a hot mixture of $\mathrm{MeOH}$ and $\mathrm{EtOH}(14$ and $10 \mathrm{~mL})$ was added dropwise to a methanolic solution $(8 \mathrm{~mL})$ containing $22.4 \mathrm{mg}$ of KSCN, $32.2 \mathrm{mg}$ of $\mathrm{FeSO}_{4} \cdot 7 \mathrm{H}_{2} \mathrm{O}$, and a catalytic amount of ascorbic acid (to avoid the $\mathrm{Fe}^{\mathrm{II}}$ to $\mathrm{Fe}^{\mathrm{III}}$ oxidation process). An instantaneous precipitation of a dark red solid was observed, and the mixture was
stirred for an additional $30 \mathrm{~min}$. Afterward, the solid was filtered off, washed with methanol, and dried under vacuum. Anal. Calcd for $\mathrm{C}_{22} \mathrm{H}_{18} \mathrm{FeN}_{6} \mathrm{~S}_{2}: \mathrm{C}, 54.33 ; \mathrm{N}, 17.28 ; \mathrm{H}, 3.73$. Found: $\mathrm{C}, 53.84 ; \mathrm{N}$, 16.74; H, 3.70 .

cis-[Fe(bqen)(NCSe) $)_{2}$ (2, Polymorph I). A $9 \mathrm{~mL}$ methanol solution consisting of $24.8 \mathrm{mg}$ of $\mathrm{KSeCN}, 24.0 \mathrm{mg}$ of $\mathrm{FeSO}_{4} \cdot 7 \mathrm{H}_{2} \mathrm{O}$, and a few milligrams of ascorbic acid (to avoid the $\mathrm{Fe}^{\mathrm{II}}$ oxidation) was treated with a solution of $27.1 \mathrm{mg}$ of bqen in $14 \mathrm{~mL}$ of hot ethanol. From almost the first drop a red precipitate was observed. The mixture was stirred for an additional $30 \mathrm{~min}$, and the red solid was filtered off, washed with methanol, and dried under vacuum. Anal. Calcd for $\mathrm{C}_{22} \mathrm{H}_{18} \mathrm{FeN}_{6} \mathrm{Se}_{2}: \mathrm{C}, 45.54 ; \mathrm{N}, 14.49 ; \mathrm{H}, 3.13$. Found: C, 44.59; N, 14.35; H, 3.01 .

cis-[Ni(bqen)(NCS $\left.)_{2}\right]$ (3, Polymorph I). Crystals of 3 were obtained through a liquid to liquid diffusion method using a $10 \mathrm{~mL} \mathrm{H}$ tube. One side of the tube was filled with a $\mathrm{MeOH}$ solution $(2 \mathrm{~mL})$ of $\mathrm{Ni}\left(\mathrm{NO}_{3}\right)_{2} \cdot 6 \mathrm{H}_{2} \mathrm{O}(14.21 \mathrm{mg})$ and $\mathrm{KNCS}(9.43 \mathrm{mg})$, whereas on the other side was placed a $\mathrm{CH}_{2} \mathrm{Cl}_{2}$ solution $(0.5 \mathrm{~mL})$ of $15.35 \mathrm{mg}$ of bqen ligand. The rest of the tube was filled with methanol and sealed. Two weeks later, a mixture of pale pink hexagonal-shaped crystals (3, polymorph I) and pale pink plate-shaped crystals ( $3^{\prime}$, polymorph II) were grown within the tube, which were collected and separated with the aid of a binocular lens. Since these crystals were used only as reference of polymorphs I and II, their composition was confirmed exclusively from crystallographic analysis.

cis-[Ni(bqen)(NCSe $\left.)_{2}\right]$ (4, Polymorph I). Crystals of 4 were prepared in a way similar to that for 3 . In this case, one side of the tube was filled with a MeOH solution $(2 \mathrm{~mL})$ of $\mathrm{NiSO}_{4} \cdot 6 \mathrm{H}_{2} \mathrm{O}(18.83 \mathrm{mg})$ and $\mathrm{KNCSe}(14.08 \mathrm{mg})$. On the other side of the tube was placed a $\mathrm{CH}_{2} \mathrm{Cl}_{2}$ solution $(2 \mathrm{~mL}$ ) of $15.35 \mathrm{mg}$ of bqen. The rest of the tube was filled with methanol and sealed. After 3 weeks a pure phase made up of pale orange plate-shaped single crystals was formed. Similarly to 3 and $3^{\prime}$, the composition of 4 was confirmed exclusively from crystallographic analysis.

cis-[Fe(bqen)(NCS) $)_{2}$ (1', Polymorph II). Crystals of 1' were obtained by diffusion methods using a layering tube, where an aqueous solution $(10 \mathrm{~mL})$ of $\mathrm{Fe}\left(\mathrm{ClO}_{4}\right)_{2} \cdot 6 \mathrm{H}_{2} \mathrm{O}(30 \mathrm{mg})$ was poured at first. Then, an interlayer of acetone/water $(1 / 1,4 \mathrm{~mL})$ was deposited on the previous aqueous phase and, finally, an acetone solution $(10 \mathrm{~mL})$ of bqen ligand $(34.3 \mathrm{mg}$ ) and $\mathrm{KSCN}(14.9 \mathrm{mg})$ was layered on the top of the interlayer. One week later hexagonal orange crystals of 1' were collected from the middle of the tube. Anal. Calcd for $\mathrm{C}_{22} \mathrm{H}_{18} \mathrm{FeN}_{6} \mathrm{~S}_{2}$ : C, 54.33; N, 17.28; H, 3.73. Found: C, 53.89; N, 16.95; H, 3.77.

cis-[Fe(bqen)(NCSe) $\left.)_{2}\right]$ (2', Polymorph II). Crystals of 2' were prepared through a strategy analogous to that used for obtaining $1^{\prime}$ but replacing KNCS with KSeCN (22.2 mg). Hexagonal orange crystals were observed in the middle part of the tube around 1 week after its preparation. Anal. Calcd for $\mathrm{C}_{22} \mathrm{H}_{18} \mathrm{FeN}_{6} \mathrm{Se}_{2}$ : C, 45.54; N, 14.49; H, 3.13. Found: C, 45.66; N, 14.85; H, 3.21.

cis-[Ni(bqen)(NCS) $)_{2}$ (3', Polymorph II). Crystals of 3' were obtained in the same batch as 3 (see above). They crystallize as hexagonal pale pink plates that represent the majority of the product. The composition of $3^{\prime}$ was confirmed exclusively from crystallographic analysis.

cis-[Ni(bqen)(NCSe) $)_{2}$ (4', Polymorph II). Crystals of 4' were obtained as a pure phase by diffusion methods using an $\mathrm{H}$-shaped tube. In one side was placed a mixture of $11.62 \mathrm{mg}$ of $\mathrm{NiCl}_{2} \cdot \mathrm{H}_{2} \mathrm{O}$ and $14.08 \mathrm{mg}$ of $\mathrm{KSCN}$ in $\mathrm{MeOH}(1.5 \mathrm{~mL})$, while a solution of bqen ligand in $\mathrm{CH}_{2} \mathrm{Cl}_{2}(0.5 \mathrm{~mL})$ was poured into the other side. The tube 
was finally filled with $\mathrm{MeOH}$ and sealed. Orange crystals of 4' were collected 4 weeks later. The composition of $4^{\prime \prime}$ was confirmed exclusively from crystallographic analysis.

Physical Measurements. Variable-temperature magnetic susceptibility data were recorded with a Quantum Design MPMS2 SQUID magnetometer equipped with a $7 \mathrm{~T}$ magnet, operating at $1 \mathrm{~T}$ and at temperatures of 1.8-400 K. Experimental susceptibilities were corrected for diamagnetism of the constituent atoms by the use of Pascal's constants. Powder X-ray measurements were performed on a PANalytical Empyrean X-ray powder diffractometer (monochromatic $\mathrm{Cu} \mathrm{Ka}$ radiation). Calorimetric measurements were performed using a Mettler Toledo DSC 821e differential scanning calorimeter. Low temperatures were obtained with an aluminum block attached to the sample holder, refrigerated with a flow of liquid nitrogen, and stabilized at a temperature of $110 \mathrm{~K}$. The sample holder was kept in a drybox under a flow of dry nitrogen gas to avoid water condensation. The measurements were carried out using around $10 \mathrm{mg}$ of 1', 2' (single crystals) or 2 (microcrystalline sample) sealed in aluminum pans with a mechanical crimp. Temperature and heat flow calibrations were made with standard samples of indium by using its melting transition $\left(429.6 \mathrm{~K}, 28.45 \mathrm{~J} \mathrm{~g}^{-1}\right)$. An overall accuracy of $\pm 0.2 \mathrm{~K}$ in temperature and $\pm 2 \%$ in the heat capacity is estimated. The uncertainty increases for the determination of the anomalous enthalpy and entropy due to the subtraction of an unknown baseline.

Single-Crystal X-ray Diffraction. Single-crystal X-ray data were collected on an Oxford Diffraction Supernova diffractometer using graphite-monochromated Mo Ka radiation $(\lambda=0.71073 \AA$ ). A multiscan absorption correction was performed. The structures were matrix least squares on $\mathrm{F}^{2}$ using SHELXL-2014. ${ }^{28}$ Non-hydrogen atoms were refined anisotropically, and hydrogen atoms were placed in calculated positions, refined using idealized geometries (riding model), and assigned fixed isotropic displacement parameters.

Responses to type $\mathrm{B}$ alerts appearing in some title compounds are provided in the corresponding CIF files and are related to low diffraction intensity of the crystals. Nevertheless, the crystallographic data fully convey all the chemical and structural meaning required to explain correctly the structures and the spin crossover behavior in this series of compounds. Supplementary crystallographic CIF data (CCDC 1572177 (1'-HS), 1572178 (1'-LS), 1572179 (2'-HS), 1572180 (2'-LS), 1572181 (3), 1572182 (4), 1572183 (3'), and $1572184\left(4^{\prime}\right)$ ) can be obtained free of charge from the Cambridge Crystallographic Data Centre.

\section{ASSOCIATED CONTENT}

\section{Supporting Information}

The Supporting Information is available free of charge on the ACS Publications website at DOI: 10.1021/acs.inorgchem.7b02272.

Experimental and calculated XRPD patterns for 1' and 2', crystallographic parameters for 1', 2', 3, 3', 4, and 4', selected bond lengths and angles for polymorph I $(3,4)$, intermolecular $\mathrm{C} \cdots \mathrm{C}$ contacts for polymorphs I and II of $\left[\mathrm{Ni}(\right.$ bqen $\left.)(\mathrm{NCX})_{2}\right] \quad(\mathrm{X}=\mathrm{S}, \mathrm{Se})\left(3,3^{\prime}, 4\right.$, and 4'), selected bond lengths and angles for polymorph II (1', $\left.2^{\prime}, 3^{\prime}, 4^{\prime}\right)$, crystal packing of polymorphs I and II for $\left[\mathrm{Ni}(\right.$ bqen $\left.)(\mathrm{NCX})_{2}\right](\mathrm{X}=\mathrm{S}, \mathrm{Se})\left(3,3^{\prime}, 4\right.$, and $\left.4^{\prime}\right)$, and intermolecular $\mathrm{C} \cdots \mathrm{C}$ contacts for $\left[\mathrm{Fe}(\right.$ bqen $\left.)(\mathrm{NCX})_{2}\right](\mathrm{X}$ $=\mathrm{S}, \mathrm{Se})$ polymorph II (PDF)

\section{Accession Codes}

CCDC 1572177-1572184 contain the supplementary crystallographic data for this paper. These data can be obtained free of charge via www.ccdc.cam.ac.uk/data_request/cif, or by emailing data_request@ccdc.cam.ac.uk, or by contacting The Cambridge Crystallographic Data Centre, 12 Union Road, Cambridge CB2 1EZ, UK; fax: +44 1223336033.

\section{AUTHOR INFORMATION}

\section{Corresponding Authors}

${ }^{\star}$ E-mail for C.B.-M.: Carlos.Bartual@uv.es.

${ }^{\star}$ E-mail for J.A.R.: jose.a.real@uv.es.

ORCID 0

José Antonio Real: 0000-0002-2302-561X

Notes

The authors declare no competing financial interest.

\section{ACKNOWLEDGMENTS}

We thank the Spanish Ministerio de Economia y Competitividad (MINECO) and FEDER funds (CTQ2013-46275-P and CTQ2016-78341-P and Unidad de Excelencia Maria de Maeztu MDM-2015-0538), Generalitat Valenciana (PROMETEO/2016/147), and EU Framework Program for Research and Innovation (RISE project number 734322). F.J.V.-M. thanks MINECO for a predoctoral FPI grant.

\section{REFERENCES}

(1) (a) König, E. Nature and dynamics of the spin-state interconversion in metal-complexes. Struct. Bonding (Berlin, Ger.) 1991, 76, 51-152. (b) Gutlich, P.; Hauser, A.; Spiering, H. Thermal and optical switching of iron(II) complexes. Angew. Chem., Int. Ed. Engl. 1994, 33, 2024-2054. (c) Real, J. A.; Gaspar, A. B.; Niel, V.; Muñoz, M. C. Communication between iron(II) building blocks in cooperative spin transition phenomena. Coord. Chem. Rev. 2003, 236, 121-141. (d) Gutlich, P.; Goodwin, H. A. Spin crossover in transition metal compounds I-III. Top. Curr. Chem. 2004, 234, 1. (e) Real, J. A.; Gaspar, A. B.; Muñoz, M. C. Thermal, pressure and light switchable spin-crossover materials. Dalton Trans. 2005, 2062-2079. (f) Bousseksou, A.; Molnar, G.; Salmon, L.; Nicolazzi, W. Molecular spin crossover phenomenon: recent achievements and prospects. Chem. Soc. Rev. 2011, 40, 3313-3335. (g) Spin-crossover materials: properties and applications; Halcrow, M. A., Ed.; Wiley: Hoboken, NJ, 2013.

(2) Galet, A.; Gaspar, A. B.; Muñoz, M. C.; Bukin, G. V.; Levchenko, G.; Real, J. A. Tunable bistability in a three-dimensional spin-crossover sensory- and memory-functional material. Adv. Mater. 2005, 17, 29492953.

(3) Bousseksou, A.; Negre, N.; Goiran, M.; Salmon, L.; Tuchagues, J.P.; Boillot, M.-L.; Boukheddaden, K.; Varret, F. Dynamic triggering of a spin-transition by a pulsed magnetic field. Eur. Phys. J. B 2000, 13, 451-456.

(4) Decurtins, S.; Gutlich, P.; Hasselbach, K. M.; Hauser, A.; Spiering, H. Light-induced excited-spin-state trapping in iron(II) spincrossover systems. Optical spectroscopic and magnetic susceptibility study. Inorg. Chem. 1985, 24, 2174-2178.

(5) (a) Ohba, M.; Yoneda, K.; Agustí, G.; Muñoz, M. C.; Gaspar, A. B.; Real, J. A.; Yamasaki, M.; Ando, H.; Nakao, Y.; Sakaki, S.; Kitagawa, $\mathrm{S}$. Bidirectional chemo-switching of spin state in a microporous framework. Angew. Chem., Int. Ed. 2009, 48, 4767-4771. (b) Agustí, G.; Ohtani, R.; Yoneda, K.; Gaspar, A. B.; Ohba, M.; Sanchez-Royo, J. F.; Muñoz, M. C.; Kitagawa, S.; Real, J. A. Oxidative addition of halogens on open metal sites in a microporous spin-crossover coordination polymer. Angew. Chem., Int. Ed. 2009, 48, 8944-8947. (c) Southon, P. D.; Liu, L.; Fellows, E. A.; Price, D. J.; Halder, G. J.; Chapman, K. W.; Moubaraki, B.; Murray, K. S.; Letard, J.-F.; Kepert, C. J. Dynamics interplay between spin-crossover and host-guest function in a nanoporous metal-organic framework material. J. Am. Chem. Soc. 2009, 131, 10998-11009. (d) Arcís-Castillo, Z.; MuñozLara, F. J.; Muñoz, M. C.; Aravena, D.; Gaspar, A. B.; Sanchez-Royo, J. F.; Ruiz, E.; Ohba, M.; Matsuda, R.; Kitagawa, S.; Real, J. A. Reversible chemisorption of sulfur dioxide in a spin crossover porous coordination polymer. Inorg. Chem. 2013, 52, 12777-12783. (e) Muñoz, M. C.; Real, J. A. Thermo-, piezo-, photo- and chemoswitchable spin crossover iron(II)-metallocyanate based coordination polymers. Coord. Chem. Rev. 2011, 255, 2068-2093. (f) Ni, Z.-P.; Liu, 
J.-L.; Hoque, N.; Liu, W.; Li, J.-Y.; Chen, Y.-C.; Tong, M.-L. Recent advances in guest effects on spin-crossover behavior in Hofmann-type metal-organic frameworks. Coord. Chem. Rev. 2017, 335, 28-43.

(6) (a) Letard, J.-F.; Guionneau, P.; Goux-Capes, L. Towards spin crossover applications. Top. Curr. Chem. 2004, 235, 221-249. (b) Sato, O. Dynamic molecular crystals with switchable physical properties. Nat. Chem. 2016, 8, 644-656.

(7) Guitlich, P.; Garcia, Y.; Goodwin, H. A. Spin crossover phenomena in Fe(II) complexes. Chem. Soc. Rev. 2000, 29, 419-427.

(8) (a) Halcrow, M. A. Spin-crossover compounds with wide thermal hysteresis. Chem. Lett. 2014, 43, 1178-1188. (b) Halcrow, M. A. Structure: function relationships in molecular spin-crossover complexes. Chem. Soc. Rev. 2011, 40, 4119-4142.

(9) (a) Luo, Y.-H.; Chen, L.; Wang, J.-W.; Wang, M.-X.; Zhang, Y.W.; Sun, B.-W. Ligand field tuned spin crossover for an iron(II)di(diamine) system. Inorg. Chim. Acta 2016, 450, 8-11. (b) Zheng, S.; Siegler, M. A.; Roubeau, O.; Bonnet, S. Influence of selenocyanate ligands on the transition temperature and cooperativity of bapbpybased Fe(II) spin-crossover compounds. Inorg. Chem. 2014, 53, 13162-13173.

(10) Tao, J.; Wei, R.-J.; Huang, R.-B.; Zheng, L.-S. Polymorphism in spin-crossover systems. Chem. Soc. Rev. 2012, 41, 703-737.

(11) (a) Ozarowski, A.; McGarvey, B. R.; Sarker, A. B.; Drake, J. E. EPR study of manganese(II) in two crystalline forms of bis $\left(2,2^{\prime}\right.$-bi-2thiazoline)bis(thiocyanato)iron and the high-spin-low-spin transition that occurs in only one form. X-ray structure determination of both forms. Inorg. Chem. 1988, 27, 628-635. (b) Galet, A.; Gaspar, A. B.; Muñoz, M. C.; Levchenko, G.; Real, J. A. Pressure effect and crystal structure reinvestigations on the spin crossover system: [Fe$\left.(\mathrm{bt})_{2}(\mathrm{NCS})_{2}\right]$ (bt $=2,2^{\prime}$-bithiazoline) polymorphs A and B. Inorg. Chem. 2006, 45, 9670-9679.

(12) $\theta$ is defined as $\sum_{i=1}^{24}\left(60-\theta_{i}\right), \theta_{i}$ being the angle generated by superposition of two opposite faces of the octahedron (there are four pairs of such superpositions with six $\theta$ values for each). $\sum$ represents 12 cis $\mathrm{N}-\mathrm{Fe}-\mathrm{N}$ angles in the coordination sphere $\sum_{\mathrm{i}}{ }^{12}{ }_{i l}|\varphi-90|$. (13) (a) Moliner, N.; Muñoz, M. C.; van Koningsbruggen, P. J.; Real, J. A. Spin crossover in six-coordinate $\left[\mathrm{Fe}(\mathrm{L})_{2}(\mathrm{NCX})_{2}\right]$ compounds with $\mathrm{L}=\mathrm{DPQ}=2,3$-bis-(2'-pyridyl)-quinoxaline, $\mathrm{ABPT}=4$-amino3,5-bis(pyridin-2-yl)-1,2,4-triazole and $X=S$, Se: synthesis, magnetic properties and single crystal studies. Inorg. Chim. Acta 1998, 274, 1-6. (b) Moliner, N.; Muñoz, M. C.; Letard, S.; Letard, J.-F.; Solans, X.; Burriel, R.; Castro, M.; Kahn, O.; Real, J. A. Spin-crossover in the

$\left[\mathrm{Fe}(\mathrm{abpt})_{2}(\mathrm{NCX})_{2}\right] \quad(\mathrm{X}=\mathrm{S}, \mathrm{Se})$ system: structural, magnetic calorimetric and photomagnetic studies. Inorg. Chim. Acta 1999, 291, 279-288. (c) Gaspar, A. B.; Muñoz, M. C.; Moliner, N.; Ksenofontov, V.; Levchenko, G.; Gutlich, P.; Real, J. A. Polymorphism and pressure driven thermal spin crossover phenomenon in $\left[\mathrm{Fe}(\mathrm{abpt})_{2}(\mathrm{NCX})_{2}\right](\mathrm{X}$ $=\mathrm{S}, \mathrm{Se})$ : synthesis, structure and magnetic properties. Monatsh. Chem. 2003, 134, 285-294.

(14) (a) Marchivie, M.; Guionneau, P.; Letard, J.-F.; Chasseau, D. Towards direct correlations between spin-crossover and structural features in iron(II) complexes. Acta Crystallogr., Sect. B: Struct. Sci. 2003, 59, 479-486. (b) Letard, J.-F.; Guionneau, P.; Rabardel, L.; Howard, J. A. K.; Goeta, A. E.; Chasseau, D.; Kahn, O. Structural, magnetic, and photomagnetic studies of a mononuclear iron(II) derivative exhibiting and exceptionally abrupt spin transition. Lightinduced thermal hysteresis phenomenon. Inorg. Chem. 1998, 37, 4432-4441. (c) Letard, J.-F.; Montant, S.; Guionneau, P.; Martin, P.; Le Calvez, A.; Freysz, E.; Chasseau, D.; Lapouyade, R.; Kahn, O. Large negative cubic hyperpolarizability for the spin-crossover compound cis-bis(thiocyanato)bis[N-(2-pyridylmethylene)aminobiphenyl]iron(II). Chem. Commun. 1997, 8, 745-746.

(15) Matouzenko, G. S.; Bousseksou, A.; Lecocq, S.; van Koningsbruggen, P. J.; Perrin, M.; Kahn, O.; Collet, A. Polymorphism in spin transition systems. Crystal structure, magnetic properties, and Mössbauer spectroscopy of three polymorphic modifications of $\left[\mathrm{Fe}(\mathrm{DPPA})(\mathrm{NCS})_{2}\right]$ [DPPA (3-aminopropyl)bis(2-pyridylmethyl)amine]. Inorg. Chem. 1997, 36, 5869-5879.
(16) Hagiwara, H.; Okada, S. A polymorphism-dependent $T_{1 / 2}$ shift of $100 \mathrm{~K}$ in a hysteretic spin-crossover complex related to differences in intermolecular weak $\mathrm{CH} \cdots \mathrm{X}$ hydrogen bonds $(\mathrm{X}=\mathrm{S}$ vs. $\mathrm{S}$ and $\mathrm{N})$. Chem. Commun. 2016, 52, 815-818.

(17) (a) Bonnet, S.; Siegler, M. A.; Sanchez Costa, J.; Molnar, G.; Bousseksou, A.; Spek, A. L.; Gamez, P.; Reedijk, J. A two-step spin crossover mononuclear iron(II) complex with a [HS-LS-LS] intermediate phase. Chem. Commun. 2008, 5619-5621. (b) ArcísCastillo, Z.; Zheng, S.; Siegler, M. A.; Roubeau, O.; Bedoui, S.; Bonnet, S. Tuning the transition temperature and cooperativity of bapbpybased mononuclear spin-crossover compounds: interplay between molecular and crystal engineering. Chem. - Eur. J. 2011, 17, 1482614836 .

(18) Brefuel, N.; Shova, S.; Lipkowski, J.; Tuchagues, J.-P. Fe ${ }^{\mathrm{II}}$ bistable materials based on dissymmetrical ligands: $\mathrm{N}_{4}$ Schiff bases including 2-pyridyl and 5-methylimidazol-4-yl ring. Chem. Mater. 2006, 18, 5467-5479.

(19) England, J.; Britovsek, G. J. P.; Rabadia, N.; White, A. J. P. Ligand topology variations and the importance of ligand field strength in non-heme iron catalized oxidations of alkanes. Inorg. Chem. 2007, 46, 3752-3767.

(20) (a) Slichter, C. P.; Drickamer, H. G. Pressure-induced electronic changes in compounds of iron. J. Chem. Phys. 1972, 56, 2142-2160. (b) Martin, J. P.; Zarembowitch, J.; Bousseksou, A.; Dworkin, A.; Haasnoot, J. G.; Varret, F. Solid state effects on spin transitions: magnetic, calorimetric, and Mössbauer-effectproperties of $\left[\mathrm{Fe}_{\mathrm{x}} \mathrm{Co}_{1-\mathrm{x}}\left(4,4^{\prime} \text {-bis-1,2,4-triazole }\right)_{2}(\mathrm{NCS})_{2}\right] \cdot \mathrm{H}_{2} \mathrm{O}$ mixed-crystal compounds. Inorg. Chem. 1994, 33, 6325-6333. (c) Martin, J. P.; Zarembowitch, J.; Dworkin, A.; Haasnoot, J. G.; Codjovi, E. Solid-state effects in spin transitions: role of iron(II) dilution in the magnetic and calorimetric properties of the series $\left[\mathrm{Fe}_{\mathrm{x}} \mathrm{Ni}_{1-\mathrm{x}}\left(4,4^{\prime}\right.\right.$-bis $(1,2,4$-triazole) $\left.)_{2}(\mathrm{NCS})_{2}\right] \cdot \mathrm{H}_{2} \mathrm{O}$. Inorg. Chem. 1994, 33, 2617-2623.

(21) (a) Sunatsuki, Y.; Ikuta, Y.; Matsumoto, N.; Ohta, H.; Kojima, M.; Iijima, S.; Hayami, S.; Maeda, Y.; Kaizaki, S.; Dahan, F.; Tuchagues, J. P. An unprecedented homochiral mixed-valence spincrossover compound. Angew. Chem., Int. Ed. 2003, 42, 1614-1618. (b) Hashibe, T.; Fujinami, T.; Furusho, D.; Matsumoto, N.; Sunatsuki, Y. Chiral spin crossover iron(II) complex, fac- $\wedge-\left[\mathrm{Fe}^{\mathrm{II}}(\mathrm{HLR})_{3}\right]\left(\mathrm{ClO}_{4}\right)_{2}$. EtOH (HLR = 2-methylimidazol-4-yl-methylideneamino-R-(+)-1methylphenyl). Inorg. Chim. Acta 2011, 375, 338-342. (c) Sunatsuki, Y.; Miyahara, S.; Sasaki, Y.; Suzuki, T.; Kojima, M.; Matsumoto, N. Conglomerate crystallization, chiral recognition and spin-crossover in a host-guest complex consisting of Fe III complexes (host) and $\left[\mathrm{Cr}(\mathrm{ox})_{3}\right]^{3-}$ (guest). CrystEngComm 2012, 14, 6377-6380. (d) Ohkoshi, S.; Takano, S.; Imoto, K.; Yoshikiyo, M.; Namai, A.; Tokoro, H. 90-degree optical switching of output second-harmonic light in chiral photomagnet. Nat. Photonics 2013, 8, 65-71. (e) Liu, W.; Bao, X.; Mao, L. L.; Tucek, J.; Zboril, R.; Liu, J. L.; Guo, F. S.; Ni, Z. P.; Tong, M. L. A chiral spin crossover metal-organic framework. Chem. Commun. 2014, 50, 4059-4061. (f) Romero-Morcillo, T.; ValverdeMuñoz, F. J.; Muñoz, M. C.; Herrera, J. M.; Colacio, E.; Real, J. A. Two-step spin crossover behaviour in the chiral one-dimensional coordination polymer $\left[\mathrm{Fe}(\mathrm{HAT})(\mathrm{NCS})_{2}\right]_{\infty}$. RSC Adv. 2015, 5, 69782-69789. (g) Sekimoto, Y.; Karim, M. R.; Saigo, N.; Ohtani, R.; Nakamura, M.; Hayami, S. Crystal structures and spin-crossover behavior of iron(II) complexes with chiral and racemic ligands. Eur. J. Inorg. Chem. 2017, 2017, 1049-1053.

(22) Sorai, M.; Seki, S. Phonon coupled cooperative low-spin ${ }^{1} A_{1}$ high-spin ${ }^{5} \mathrm{~T}_{2}$ transition in $\left[\mathrm{Fe}(\text { phen })_{2}(\mathrm{NCS})_{2}\right]$ and $[\mathrm{Fe}-$ (phen $)_{2}(\mathrm{NCSe})_{2}$ ] crystals. J. Phys. Chem. Solids 1974, 35, 555-570. (23) König, E.; Ritter, G.; Dengler, J.; Nelson, J. Detailed study of the quintet $\leftrightarrow$ singlet spin transition in bis(selenocyanato)bis(2,2'bithiazoline)iron(II). Inorg. Chem. 1989, 28, 611.

(24) Letard, J. F.; Guionneau, P.; Codjovi, E.; Lavastre, O.; Bravic, G.; Chasseau, D.; Kahn, O. Wide Thermal Hysteresis for the Mononuclear Spin-Crossover Compound cis-Bis(thiocyanato)bis[N(2'-pyridylmethylene)-4-(phenylethynyl)anilino]iron(II). J. Am. Chem. Soc. 1997, 119, 10861-10862. 
(25) Tailleur, E.; Marchivie, M.; Daro, N.; Chastanet, G.; Guionneau, $\mathrm{P}$. Thermal spin-crossover with a large hysteresis spanning room temperature in a mononuclear complex. Chem. Commun. 2017, 53, $4763-4766$.

(26) Sheu, C.-F.; Chen, K.; Chen, S.-M.; Wen, Y.-S.; Lee, G.-H.; Chen, J.-M.; Lee, J.-F.; Cheng, B. M.; Sheu, H. S.; Yasuda, N.; Ozawa,

Y.; Toriumi, K.; Wang, Y. Structure and electronic configuration of an iron(II) complex in a LIESST state: a pump and probe method. Chem. - Eur. J. 2009, 15, 2384-2393.

(27) Arcís-Castillo, Z.; Piñeiro-Lopez, L.; Muñoz, M. C.; Ballesteros, R.; Abarca, B.; Real, J. A. Structural, magnetic and calorimetric studies of a crystalline phase of the spin crossover compound [Fe(tzpy $)_{2}(\mathrm{NCSe})_{2}$ ]. CrystEngComm 2013, 15, 3455-3462.

(28) Sheldrick, G. M. SHELXL-2014; University of Göttingen, Götingen, Germany, 2014. 